\title{
Nuclear GSK-3 $\beta$ and Oncogenic KRas Promote Expansion of Terminal Duct Cells and the Development of Intraductal Papillary Mucinous Neoplasm
}

Li Ding ${ }^{1 *}$, Kaely Roeck ${ }^{1}$, Cheng Zhang ${ }^{2}$, Brooke Zidek ${ }^{1}$, Esther Rodman ${ }^{1}$, Yasmin Genevieve Hernandez-Barco ${ }^{3}$, Jin-San Zhang ${ }^{1,4}$, William R. Bamlet ${ }^{5}$, Ann L. Oberg ${ }^{5}$, Lizhi Zhang $^{6}$, Nabeel Bardeesy ${ }^{3}, \mathrm{Hu} \mathrm{Li}^{2}$, and Daniel D. Billadeau ${ }^{1 *}$

${ }^{1}$ Division of Oncology Research, ${ }^{2}$ Department of Molecular and Experimental Therapeutics, ${ }^{5}$ Department of Health Sciences Research, ${ }^{6}$ Department of Laboratory Medicine and Pathology, College of Medicine, Mayo Clinic, Rochester, MN 55905, USA. ${ }^{3}$ Center for Cancer Research, Harvard Medical School, Boston, MA 02115, USA. ${ }^{4}$ Center for Precision Medicine, The First Affiliated Hospital of Wenzhou Medical University; Institute of Life Science, Wenzhou University, Zhejiang, China

Running title: Nuclear GSK-3ß and oncogenic KRas promote IPMN development

Keywords: GSK-3ß, Oncogenic KRas, Pancreatic Cancer, Intraductal Papillary Mucinous Neoplasm (IPMN), terminal ducts.

Financial support: This work was supported by the Pancreatic Cancer SPORE grant CA102701 and Center for Biomedical Discovery Pilot Award to D.D. Billadeau, and a Fraternal Order of Eagles and Center for Biomedical Discovery Fellowship grant to L.D. We also acknowledge support from the Transgenic and Knockout, and Genome Analysis Shared Resources of the Mayo Clinic Cancer Center grant P30 CA015083.

${ }^{*}$ Corresponding Author: Correspondence and request for materials should be sent to L.D. (ding.li@mayo.edu) and D.D.B. (billadeau.daniel@mayo.edu), Division of Oncology 
Research and Schulze Center for Novel Therapeutics, Mayo Clinic, 200 First ST SW, Rochester, MN 55905.

Conflict of interest: The authors declare no potential conflict of interest.

Word count: 6037

Total number of figures and tables: 7 Figures 


\section{Abstract}

Intraductal papillary mucinous neoplasm (IPMN) represents one type of pancreatic ductal adenocarcinoma (PDA) precursor lesion, however its cell-of-origin remains unclear. Here we describe a new mouse model in which pancreas-specific Cre activation of a nuclear glycogen synthase kinase- $3 \beta$ transgene is combined with oncogenic KRas (referred to as KNGC). KNGC mice show accumulation of neoplastic ductal cells at 4-weeks that progressively develop into IPMN with low-grade dysplasia in advanced age. RNA-sequencing identified expression of several terminal duct cell lineage genes including Agr2 and Aqp5. Interestingly, Aqp5, a water channel, was found to be required for the development of IPMN lesions in KNGC mice. Staining of human IPMN samples indicates that these preneoplastic lesions also arise from expansion of the terminal duct population. Altogether, these data highlight the utility of the KNGC model for understanding the biology of IPMN and potential utility in defining predictive biomarkers of IPMN - PDA development.

\section{Statement of significance}

Understanding the cell-of-origin of IPMN is crucial to developing early detection methods that specifically target aggressive precursors of PDA. This work, using a novel mouse model, identifies Aqp5-modulated development of Agr2 ${ }^{+}$terminal ducts that could potentially serve as a clinical biomarker for IPMN. 


\section{Introduction}

Pancreatic ductal adenocarcinoma (PDA) is predicted to be the second leading cause of cancer-related deaths in the USA by 2030 . The 5-year relative survival rate of all stages combined is less than $10 \%$, with $80 \%$ of patients having a locally advanced tumor at diagnosis, which highlights the significant need for the development of novel earlydetection strategies and models to understand PDA tumor development (1-4).

Three major types of morphologically distinct PDA precursors have been identified to date, including pancreatic intraepithelial neoplasia (PanIN), intraductal papillary mucinous neoplasm (IPMN) and mucinous cystic neoplasm (5), each likely have an unique impact on disease biology, response to therapy and prognosis $(6,7)$. Although there has been an increase in understanding of PDA disease progression, established from well appreciated studies of patient samples and the development of genetically engineered mouse models (GEMM) (8-10), the cell-of-origin of PDA remains controversial.

Sequencing from human specimens has shown an overlap of somatic mutations between PanIN and IPMN, including the activating mutation of KRas, the most frequent and earliest genetic alteration in PDA $(11,12)$, and the secondary loss-of-function mutation of tumor suppressors TP53 and SMAD4/DPC4, particularly in high-grade lesions (13). Moreover, lineage-tracing experiments and cell-type specific activation of oncogenic KRas coupled to other genetic alterations have been conducted and the collective data demonstrate that, although acinar cells possess the highest plasticity to be transformed and are responsible for most PanIN and IPMN lesions through acinar- 
to-ductal metaplasia (ADM), ductal cells harboring oncogenic KRas can also give rise to precursor lesions sharing similar histology features, and might also serve as a cell-oforigin for PDA $(9,10,14-16)$. Thus, delineating the origin of PDA precursor lesions with deeper molecular insight could facilitate the development of clinical tools for earlydetection and improve PDA patient outcomes in the clinic.

Glycogen synthase kinases, GSK-3 $\alpha$ and GSK-3 $\beta$, were originally identified as key enzymes regulating glycogen metabolism (17-19). However, accumulating evidence has suggested a role for these kinases in several human malignancies (20-22) and has identified them as therapeutic targets in pancreatic cancer (23). Significantly, GSK-3ß is overexpressed in PDA and aberrant nuclear accumulation, as well as increased mRNA expression of GSK-3 $\beta$, has been associated with high-grade tumors $(24,25)$. Moreover, our prior studies showed that mutant KRas increases GSK-3 $\beta$ gene expression in vivo and in vitro $(26,27)$. However, the studies conducted so far to address the multifaceted role of GSK-3 $\beta$ in pancreatic cancer in vivo have mostly relied on loss-of-function approaches including knockout mice or GSK-3 inhibitors (23). The role of nuclear GSK$3 \beta$ in pancreatic cancer progression in vivo, particularly as it pertains to PDA precursor lesion development, is unknown.

To address this, we generated a novel pancreas-specific nuclear GSK-3 $\beta$ expression and oncogenic KRas activation model (KNGC) to investigate the function of nuclear GSK-3 $\beta$ and its impact on PDA precursor lesion initiation and progression. Unexpectedly, we observed profound pancreatic cyst development and expansion of ductal cells in 4-week old KNGC mice and subsequent low-grade IPMN lesions in KNGC mice of advanced age. RNA-sequencing data indicated that nuclear GSK-3 $\beta$ and 
oncogenic KRas reprogrammed pancreatic progenitor cells toward the ductal lineage, resulting in a loss of acinar cells and the expansion of ductal cells expressing anterior gradient 2 (Agr2) and Aquaporin 5 (Aqp5). Agr2 and Aqp5 expression was found to be associated with the terminal or intercalated ductal cell compartment. Aqp5 knockout in KNGC mice dramatically abrogated differentiation and development of $\mathrm{Agr}^{+}$terminal ducts. Using tissue microarrays, we show that human IPMN lesions also arise from $\mathrm{Agr}^{+} / \mathrm{Aqp}^{+}$terminal ducts. Taken together, these results highlight pancreatic terminal duct cells as the likely cell-of-origin for human IPMN, and provide a novel mouse model for biomarker discovery, IPMN development and progression to PDA.

\section{Results}

\section{GSK-3 $\beta$ ablation limits oncogenic KRas induced pancreatic cancer development}

A genetically engineered mouse model, expressing activated mutant KRas (G12D) in the pancreas, develops pancreatic cancer with long latency (28), which can be substantially accelerated by experimentally inducing chronic pancreatitis or crossbreeding with mutations/deletions of the tumor suppressors TP53 or Ink4a/Arf $(29,30)$. We have previously demonstrated that GSK-3 $\beta$ expression is a target of activated KRas signaling in pancreatic cancer cells and pancreas specific deletion of GSK-3 $\beta$ in KRas mutant mice reduces cearulein-induced ADM and PanIN lesion development, while abrogating KRas mutation-dependent proliferation $(26,27)$. To examine the impact of GSK-3 $\beta$ ablation on pancreatic cancer progression, the pancreas was collected from 8- to 10-month old Pdx1-cre/LSL-KRasG12D (KC) and Pdx1cre/LSL-KRasG12D/GSK-3 $\beta^{F / F}$ (RKO) littermates (Figure 1A). The total number of 
ductal lesions and their grade were scored in representative pancreatic sections. Depletion of GSK-3 $\beta$ was confirmed by immunofluorescent staining of GSK-3 $\beta$ and the pancreatic ductal cell marker CK19. Strong GSK-3 $\beta$ signal was detected in CK19 ${ }^{+}$ neoplastic ducts from KC mice but not RKO mice (Figure 1B). Consistent with a previous report (28), the majority of pancreas tissue from 9-month old $\mathrm{KC}$ mice were replaced by metaplastic ducts and surrounded by desmoplasia (Figure 1C). In contrast, RKO mice had diminished numbers of ADM and low-grade PanIN lesions (1 and 2), as well as a reduced incidence of high-grade PanIN-3 and invasive cancer (Figure 1C and D) compared to KC mice. Since GSK-3 $\beta$ has been shown to participate in the regulation of pancreatic cancer cell proliferation $(23,27)$, we examined the proliferation of neoplastic ducts in $\mathrm{KC}$ and RKO mice. As shown in Figure $1 \mathrm{E}$ and $\mathrm{F}$, we observed an accumulation of $\mathrm{EdU}^{+} / \mathrm{CK} 19^{+}$ductal cells within neoplastic areas in $\mathrm{KC}$ mice, which were dramatically reduced in RKO mice. Taken together, these data suggest that GSK$3 \beta$ is required for oncogenic KRas-driven cell proliferation and deletion of GSK-3 $\beta$ impairs preneoplastic lesion and pancreatic cancer development in KC mice.

\section{Nuclear GSK-3 $\beta$ and oncogenic KRas promote the pancreatic ductal cells expansion and IPMN development}

We have previously shown that GSK-3 $\beta$ is overexpressed in PDA and becomes localized to the nucleus in high-grade tumors (24). To characterize the role of nuclear GSK-3 $\beta$ in pancreatic cancer development, we generated a novel pancreas-specific nuclear GSK-3 $\beta$ expression model by inserting a GSK-3 $\beta$ transgene containing an HA 
tag and a nuclear localization signal sequence into the Rosa26 locus. The transgene also contained a 5' Lox-STOP-Lox (LSL) cassette for tissues-specific activation. Mice carrying LSL-nuclear GSK-3ß (NG) were crossbred with KC mice to produce KNGC mice (Figure 2A). As shown in Figure 2B, protein extracts from both NGC and KNGC animals showed a unique HA band which was not seen in WT or KC mice. Phosphorylation of Erk1/2, a downstream target of activated KRas, was only slightly upregulated in $\mathrm{KC}$ mice due to limited formation of $\mathrm{ADM}$ and PanIN precursor lesions at this age (28). However, KNGC mice had a dramatic increase of phospho-Erk1/2, suggesting a hyper-activation of KRas signaling induced by expression of nuclear GSK$3 \beta$. Consistent with the immunoblot results, gross pathological examination revealed hallmarks of pancreatic neoplastic transformation, including visible cysts and desmoplasia in KNGC mice, but no gross pathological changes were found in the pancreas from WT, NGC and KC mice (Figure 2C).

Immunofluorescent staining confirmed that the HA-tag was widely expressed in acinar and hyperplastic ductal cells within the pancreas of NGC and KNGC mice, which was absent from WT and KC mice (Supplemental Fig. S1). Alpha-smooth muscle actin (aSMA), a marker for activated myofibroblasts, was associated with areas of metaplasia in KC mice but not with the areas of ductal hyperplasia observed in the KNGC mice (Figure 2D). Due to apparent loss of the normal physiologic function of the pancreas, KNGC mice had a significantly lower body weight across their lifespan and a dramatically shortened median survival of approximately 6 months as compared with $\mathrm{KC}$ mice (Figure 2E, F and G). Histologically, normal acinar cell clusters were rarely seen in KNGC mice. At 4 weeks of age, KNGC mice developed multifocal ductal 
structures and atypical ductal cells across the pancreas, which rapidly expanded with age (Figure $2 \mathrm{H}, \mathrm{I}$ and $\mathrm{J}$ ). Loss of ductal cell polarity, papillary architecture with increased nuclear/cytoplasmic ratio, and mucinous epithelial neoplasm were most frequently seen in 8-month old KNGC mice, representing the histological features of low-grade IPMN. Consistent with the pathologic definition of low-grade IPMN, no invasive cancer or metastases were observed in 8-month old age KNGC mice. Taken together, these data suggest that overexpression of nuclear GSK-3 $\beta$ with oncogenic KRas results in the development of low-grade IPMN lesions, a well-known precursor to PDA.

\section{Nuclear GSK-3 $\beta$ and oncogenic KRas initiate ductal hyperplasia at an early stage of pancreatic development}

It is of interest that NGC mice were indistinguishable from WT littermates in every age group (data not shown), suggesting that nuclear GSK-3 $\beta$ expression, on its own, is insufficient to drive ductal cell expansion. The induction of acute pancreatitis in KC mice leads to acinar-to-ductal metaplasia (ADM) and the generation of PanIN lesions (31). Whether nuclear GSK-3 $\beta$ might promote ADM or PanIN lesion formation following pancreas injury, independent of oncogenic KRas, was unclear. To test this, we utilized cearulein to induce acute pancreatitis in WT and NGC mice and collected the pancreas 7 days after cearulein treatment (Supplemental Fig S2A). Histopathological examination showed no significant differences in pancreas histology with minimal traces of pancreatitis (Supplemental Fig S2B). These results indicate that nuclear GSK-3ß 
expression is not sufficient to promote pancreatitis-induced ductal transformation without oncogenic KRas in vivo.

Given the ductal hyperplasia and atypia observed in immature KNGC mice, we generated a conditional model where nuclear GSK-3 $\beta$ and oncogenic KRas could be induced in the whole body of adult mice using Rosa26-Cre ${ }^{E R T}$ (KNG-R26CreER, Figure 3A). Four-weeks after tamoxifen induction, expression of HA-tag and mutant KRas were confirmed in KNG-R26CreER mice by immunoblotting (Figure 3B). Similar to a prior report (32), activation of KRas and nuclear GSK-3 $\beta$ varied in mature acinar and ductal cells of KNG-R26CreER mice as determined by immunofluorescent staining for HA (Figure 3C). Additionally, very few ADM lesions were observed in either K-R26CreER or KNG-R26CreER mice (Figure 3C). Since over 95\% of the mature pancreas is comprised of acinar cells, and the expression of HA was relatively low in mature ductal cells (Figure 3C), we next sought to examine whether nuclear GSK-3 $\beta$ expression could increase the susceptibility of pancreatic ductal cells to oncogenic KRas-initiated tumorigenesis using Krt19-Cre ${ }^{\text {ERT }}$ (KNG-Krt19CreER, Figure 3D). Surprisingly, we did not observe significant ductal metaplasia in the pancreas in either K-Krt19CreER or KNG-Krt19CreER mice 2 months following tamoxifen induction (Figure 3E). These data suggest that metaplasia induced by nuclear GSK-3 $\beta$ and oncogenic KRas does not occur in acinar or ductal cells in the adult pancreas.

Expression of $P D X-1 / I P F 1$ is believed to be the earliest identifiable marker in pancreatic progenitor cells $(28,33,34)$. Therefore, we examined the pancreata of neonatal KNGC mice, where we observed an increased number of ducts, ductal hyperplasia and enlargement, and marked increase in the number of phospho-ser10 histone $\mathrm{H} 3$ positive 
(pS10HH3+) mitotic cells (Figure 3F-K and Supplemental Fig S2C). Taken together, these data suggest that the combined expression of nuclear GSK-3 $\beta$ and oncogenic KRas promotes ductal cell expansion and proliferation very early in development, but is unable to do so in adult tissues.

\section{Transcriptional regulation of pancreatic ductal neoplasm by overexpression of nuclear GSK-3 $\beta$ and oncogenic KrasG12D activation}

To gain insight into the cell of origin and transcriptional pathways promoting the ductal hyperplasia seen in KNGC mice, we isolated RNA from the pancreas of 4-week old WT, NGC, KC and KNGC mice and performed RNA-Seq. Consistent with the unusual composition of the pancreas in KNGC mice, we detected over 9000 significantly changed genes compared to the other genotypes (Supplemental Figure S3A). KEGG signaling pathway analysis found over 1000 pathways to be significantly activated, while 100 pathways were substantially inactivated in KNGC mice as compared to KC or NGC mice (using log2FC $>2$ or log2FC $<-2$ as a cutoff, respectively; Supplemental Figure S3B). Among the signaling pathways increased in KNGC mice were those involved in differentiation, proliferation and development (Figure 4A). In contrast, genes with decreased expression were closely associated with secretion and digestion, granule formation and cellular metabolism (Figure 4B). As can been seen in Figure 4C, markers for acinar cells, normal ductal cells, human PDA precursors, and multiple subsets of pancreatic cancer associated fibroblasts (Pan-CAF) (35-38), were significantly changed in KNGC mice compared to the other genotypes (complete list can be found in 
Supplemental Excel Table S3). The differential expressions of mucin genes are associated with subtypes of IPMN (13). KNGC mice expressed a subset of mucins primarily associated with the gastric type of IPMN, including Muc5a/c and Muc6 (Figure 4D). We next validated the RNA-Seq data via quantitative PCR for two genes from each compartment (Figure 4E). In addition, significantly increased protein levels of pankeratin and Agr2, together with diminished expression of amylase, were confirmed by immunoblot (Figure 4F). Moreover, immunofluorescent staining of pancreata from KNGC mice with CK19 and amylase showed that the acinar tissue had been largely replaced with $\mathrm{CK} 19^{+}$hyperplastic ducts (Figure 4G and H and Supplemental Figure S3C and D).

Two genes that were highly upregulated in KNGC mice were Agr2 and the water channel Aqp5, both of which are expressed in PDA $(39,40)$. Therefore, we investigated the expression of Agr2 and Aqp5 in the pancreas of KNGC mice. Consistent with a previous report (41), KNGC mice showed strong Agr2 expression in close to $60 \%$ of $\mathrm{CK}_{1} 9^{+}$ducts, while similarly aged KC mice only expressed Agr2 in a limited number of metaplastic ducts (Figure $4 \mathrm{I}$ and J). Similar to Agr2 staining, Aqp5 was detected in a few early ADM lesions of $\mathrm{KC}$ mice, but had significantly higher distribution in $\mathrm{CK} 19^{+}$ducts in KNGC mice (Figure 4K and L). To determine if expression of Agr2 and Aqp5 were regulated in a GSK-3ß dependent manner, we stained Agr2 and Aqp5 in aging KC and RKO mice. Interestingly, conditional GSK-3 $\beta$ ablation in KC mice substantially limited the development of $\mathrm{Agr}^{+} / \mathrm{Aqp5}^{+}$ducts (Supplemental Figure S3E and F). Taken together, these data suggest that expression of GSK-3 $\beta$ and oncogenic KRas result in a 
transcriptional switch from pancreatic acinar cells to neoplastic ductal cells, with expression of pancreatic tumor subtype markers.

\section{Expression of nuclear GSK-3 $\beta$ with oncogenic KRas leads to the development of two distinct ductal populations}

To further characterize the neoplastic ducts arising in the KNGC model, we utilized a protocol that has been previously used to capture lectin ${ }^{+}$ductal cells from the pancreas (37). This protocol combines antibody capture of ductal cells that are recognized by the lectin-binding protein Dolichos Bifluros Agglutin (DBA) with magnetic beads, resulting in separation of a $\mathrm{DBA}^{+} / \mathrm{CK} 19^{+}$ductal cell pool from a $\mathrm{DBA}^{-}$cell population containing other cell types from within the pancreas (Figure 5A). Fluorescence microscopy confirmed the capture of DBA-FITC labeled cells from 4-week old KNGC mice (Supplemental Figure S4A). We observed equivalent expression of pan-Keratin in $\mathrm{DBA}^{-}$ and $\mathrm{DBA}^{+}$ducts, with significantly higher levels of Agr2 protein in the $\mathrm{DBA}^{-}$ductal pool as compared to the $\mathrm{DBA}^{+}$ductal pool (Figure $5 \mathrm{~B}$ and $\mathrm{C}$ ). Consistent with our immunoblotting and histology data, qRT-PCR showed that $\mathrm{DBA}^{-}$ducts from KNGC mice exhibited diminished acinar cell marker expression, but elevated ductal marker expression similar to the $\mathrm{DBA}^{+}$ductal structures. More importantly, compared to $\mathrm{DBA}^{+}$ ducts, DBA ducts from 4-week old KNGC mice had increased expression of Agr2, Aqp5 and cystic fibrosis transmembrane conductance regulator (CFTR) (Figure 5D), which is another highly induced gene in KNGC mice (Figure 4C), and has been shown to colocalize with Aqp5 in human pancreatic intercalated/terminal duct cells (42). Consistent 
with a prior report (43), isolated $\mathrm{DBA}^{-}$ductal cells from aging $\mathrm{KC}$ mice were enriched in acinar markers, while $\mathrm{DBA}^{+}$ducts possessed much higher expression of ductal markers (Figure 5D). These results indicate that the ductal cell population expanding in KNGC mice is not only different than that found in aged $\mathrm{KC}$ mice, but represents a unique ductal population lacking expression of the lectin bound by DBA.

We next examined the differential expression of Agr2 and Aqp5, along with DBA, in neoplastic ducts from KNGC mice using immunofluorescence. Co-staining of Agr2, Aqp5 and DBA-FITC showed strongly positive Agr2 and Aqp5 stained ducts that were distinct from those detected using DBA-FITC (Figure 5E). Similar staining patterns were also observed in aging KC mice (Supplemental Figure S4B). Strikingly, and consistent with the role of Agr2 in PanIN lesion initiation and PDA progression (44-46), EdU labeling showed increased DNA synthesis in $\mathrm{Agr2}^{+}$ductal cells compared to DBA-FITC ductal cells (Figure 5F and G). Similar results were seen in aging $\mathrm{KC}$ mice, where $\mathrm{EdU}^{+}$ cells also accumulated in $\mathrm{Agr}^{+}$ducts. Ablation of GSK-3 $\beta$ in $\mathrm{KC}$ mice led to reduced $\mathrm{EdU}^{+}$cell numbers, which was partially due to the limited proportion of ducts with Agr2 expression (Supplemental Figure S4C). Taken together, these data suggest that GSK$3 \beta$ and oncogenic KRas lead to the development of a $\mathrm{DBA}^{-} / \mathrm{Agr}^{+}$ductal cell pool with more proliferative potential.

\section{Aqp5 is necessary for the differentiation and growth of terminal ducts in KNGC mice}


The water channel Aqp5 was first described to localize mainly in terminal/intercalated and interlobular ducts in the human pancreas $(42,47)$, also characterized as $\mathrm{DBA}^{-}(48)$. Analysis of our RNA-seq data indicated that Aqp5 had the highest log2FC among the 19 significantly increased genes compared between both NGC and KC with WT mice (Supplemental Figure S5A and B; detailed gene list can be found in Supplemental Excel Table S4). To determine the contribution of Aqp5 to the development and growth of neoplastic ducts, especially DBA $/ \mathrm{Agr}^{+}$terminal ducts, we crossed KNGC mice with whole body Aqp5 knockout mice (49) to generate KNGCA mice (Figure 6A). Knockout of Aqp5 in 4-week old KNGCA mice was validated by qRT-PCR (Figure 6B). Although, Aqp5 staining was highly expressed in $\mathrm{DBA}^{-}$ductal cells from KNGC mice, it was diminished in KNGCA mice (Figure 6C). Histological examination revealed that the knockout of Aqp5 in KNGC mice significantly decreased the development and expansion of neoplastic ducts, when compared to similarly aged KNGC mice (Figure 6D and E). Moreover, KNGCA mice showed restored expression of acinar markers and reduced expression of Agr2 and CFTR (Figure 6F). Consistent with the expression data, KNGCA mice developed a higher percentage of amylase ${ }^{+}$acinar cells than KNGC mice (Supplemental Figure S5C and D). To further characterize the impact of Aqp5 deletion on the development of $\mathrm{Agr}^{+}$ducts and its effect on proliferation, serial sections of pancreas from KNGC and KNGCA mice were stained using a combination of Agr2 or pS10HH3 with DBA-FITC. As shown in Figure 6G, the mitotic marker, pS10HH3, was mainly localized in $\mathrm{DBA}^{-} / \mathrm{Agr}^{+}$ducts in KNGC mice (Figure $6 \mathrm{H}$ ). However, KNGCA mice showed decreased $\mathrm{pS} 10 \mathrm{HH} 3+$ cells in $\mathrm{DBA}^{-}$ducts, as well as a reduction in the percentage of $\mathrm{Agr}^{+}$ducts (Figure $6 \mathrm{H}$ ). Taken together, these data reveal an important 
role of Aqp5 in the development and growth of the $\mathrm{Agr}^{+}$terminal ductal population in KNGC mice.

\section{Differences in Agr2, Aqp5 and DBA lectin staining in human IPMN}

To investigate the distribution of $\mathrm{Agr}^{+}, \mathrm{Aqp5}^{+}$and $\mathrm{DBA}^{+}$ducts in human IPMN, we performed Agr2/DBA-FITC IF staining and Aqp5 IHC staining on serial sections from tissue microarrays containing 140 human IPMN cases (see patient demographics of TMA in Supplemental Table S5) (50). Consistent with our KNGC mouse model, the majority of IPMN cores showed positive staining of both Agr2 and Aqp5 (Core 1 and 2 in Figure 7A and B). In contrast, we observed significantly fewer cores that were $\mathrm{DBA}^{+/} \mathrm{Agr2}^{-}$(area 4 from Core 2 in Figure 7A). The strong and widespread distribution of $\mathrm{Agr}^{+} / \mathrm{Aqp}^{+} / \mathrm{DBA}^{-}$terminal ducts in the IPMN TMA were further confirmed by Hscore, as Agr2 and Aqp5 staining were much higher than the DBA-FITC staining (Figure 7C). Moreover, correlation analysis of Agr2 and Aqp5 using Hscore indicated a statistically significant correlation between Agr2 and Aqp5 in the overall samples and in the subset of IPMN with adenocarcinoma (Figure 7D). To further test the significance of $\mathrm{Agr}^{+} / \mathrm{Aqp}^{+} / \mathrm{DBA}^{-}$terminal ducts in IPMN development, we stained Agr2, Aqp5 and DBA in a previously published mouse model of IPMN, which combined mutations of KRas and GNAS (KGC) (51). Similar to the KNGC mice, IPMN lesions in the pancreas from KGC mice had higher staining for both Agr2 and Aqp5 than DBA-FITC (Supplemental Figure S6A and B). Collectively, these results support the conclusion that $\mathrm{Agr}^{+} / \mathrm{Aqp}^{+} / \mathrm{DBA}^{-}$terminal ducts serve as a cell-of-origin for human IPMN lesions. 


\section{Discussion}

In this study, we have generated a novel pancreas-specific nuclear GSK-3ß expression and oncogenic KRas mouse model to investigate the contribution of nuclear GSK-3 $\beta$ to oncogenic KRas-driven pancreatic cancer development. Surprisingly, we found that nuclear GSK-3 $\beta$ rapidly promotes pancreatic cyst development and expansion of ductal cells in 4-week old KNGC mice. In a longitudinal study of KNGC mice, we observe notable reduction of body weight, as well as shortened overall survival, which is likely a result of the dramatic loss of pancreatic acinar cells. RNA-seq of the whole pancreas identified robust expression of Agr2, Aqp5 and CFTR, which are markers of PDA precursors $(37,52)$. Consistent with previous publications $(42,45,48)$, these markers are enriched in intercalated/terminal ducts and possess a higher proliferative potential than DBA-lectin ${ }^{+}$interlobular ducts (Figure 7E). Significantly, knockout of Aqp5 in KNGC mice impaired IPMN development, indicating that Aqp5 is likely involved in terminal duct cell expansion/proliferation. We also observed the existence of widespread Agr2 $^{+} /$Aqp $^{+} / \mathrm{DBA}^{-}$ducts in human IPMNs samples, and in a mouse model for IPMN (51). Taken together, these results suggest that terminal duct cells are a likely cell-oforigin for IPMN.

Several distinct precursor lesions, including PanIN, MCN and IPMN, are associated with the development of PDA. It is appreciated that KC mice develop PDA through a conversion of acinar-to-ductal metaplasia leading to PanIN lesion formation and PDA with long latency, which can be accelerated by the deletion or activation of mutant tumor suppressors, such as p16 or TP53 $(9,10,14,15)$. Interestingly, using the same KC model, along with the addition of other oncogenes or tumor suppressors such as SMAD4, 
GNAS, Brg1, or Notch2, can result in a different progression path including the development of IPMN and MCN $(51,53,54)$, reviewed in (15). It was first demonstrated by von Figura that Brg1 deletion using the Ptf1a-Cre promoter, which has Cre activity in almost all acinar cells and a subset of duct cells, promoted KRas-driven neoplasia in adult duct cells. However, using an inducible Ptf1a-CreER, in which Cre activity is restrained to mature acinar cells, they instead found Brg1 loss protected adult acinar cells from KRas-dependent PanIN development. Their results suggest that ductal cells are responsible for the IPMN-PDA progression in the Ptf1a-Cre; LSL-KRas; Brg $1^{\mathrm{f} / \mathrm{f}}$ mouse model (54). Consistent with this study, Taki found that a Ptf1a-Cre inducible GEMM harboring GNAS ${ }^{\text {R201H }}$ and KRas ${ }^{\mathrm{G} 12 \mathrm{D}}$, two common somatic mutations found in human IPMN, cooperated to promote papillary dysplastic epithelia within dilated ducts mimicking human IPMN (53). In contrast, using inducible Ptf1a-Cre; GNAS ${ }^{\text {R201C; }}$ KRas $^{\mathrm{G} 12 \mathrm{D}}$ (KGC) showed a similar ability of acinar cells to give rise to IPMN, suggesting that it is actually underlying mutations, rather than the cell-of-origin, that are more important in IPMN development (51). Interestingly, using DBA to isolate pancreatic ductal cells from oncogenic KRas only or KRas; $\operatorname{Brg} 1^{\mathrm{f} / \mathrm{f}}$ mice (37), showed that $\mathrm{Brg} 1$ sustained mature duct cell identity in the context of oncogenic KRas, whereas loss of Brg1 led to dedifferentiation of ductal cells with higher expression of progenitor markers (55). Thus, the cell of origin in these models still remains controversial. Although the lectin-binding protein DBA has been proposed to label the entire pancreatic ductal tree, including centroacinar cells, as well as PanIN and IPMN lesions, DBA low or negative duct structures were also observed in the previous studies $(43,55)$. These DBA-negative 
structures were recognized as intercalated/terminal ducts, which possess stem cell or progenitor cell characteristics $(9,43,48)$.

In the present study, we found that expression of nuclear GSK-3 $\beta$ and KRasG12D, under control of the Pdx1-cre transgene, which is required for differentiation of all pancreatic lineages, substantially initiates ductal expansion as early as the neonatal stage. Gene expressing profiling of different mucins from our RNA-Seq analysis showed elevated expression of muc1, muc5ac and muc6, which is consistent with the gastric type of IPMN (13). In addition, RNA-Seq data also revealed increased expression of Agr2, which is a recently identified marker used to distinguish ductal-derived PDA from acinar-derived PDA (41), thus suggesting that ductal cells are the main source for dilated ducts in KNGC mice. Moreover, expression of Agr2, together with Aqp5 and CFTR, three genes which have been demonstrated to have expression in human terminal ducts $(40,45)$, were highly enriched in the DBA negative population from KNGC mice, further implicating terminal ducts as the cell-of-origin for IPMN development in the KNGC model. Significantly, KNGC mice showed a higher percentage of $\mathrm{DBA}^{-}$cells undergoing mitosis as compared to $\mathrm{DBA}^{+}$ducts. Lastly, the existence of $\mathrm{Agr}^{+} / \mathrm{Aqp}^{+}$ ductal cells as the prominent ductal cell population observed in human IPMN specimens, and the KGC mouse model, highlight terminal duct cells as the likely cell of origin in IPMN initiation.

Our previous studies, showing that deletion of GSK-3 $\beta$ in the KC model limits pancreatitis-induced acinar-to-ductal metaplasia, is in line with the data presented here, 
where genetic deletion of GSK-3 $\beta$ abrogates PanIN lesion development in aged KC mice. Taken together, these results suggest a cooperation between oncogenic KRas signaling pathways and GSK-3 $\beta$ signaling pathways leading to the development of PDA. In fact, we have previously shown that KRas signaling promotes GSK-3 $\beta$ gene expression, suggesting a possible feed-forward signaling loop (26). Indeed, we have found that GSK-3 $\beta$ becomes progressively over-expressed in human PDA and nuclear accumulated in the most aggressive tumors (24). While it is not clear what leads to the nuclear accumulation of GSK-3ß, our data shown here would suggest that nuclear GSK$3 \beta$ (comparing KNG to KNGC mice) alone cannot promote neoplastic transformation of ductal cells, but requires the cooperation of oncogenic KRas signaling. Although the mechanism by which these two signaling pathways are promoting the expansion of terminal duct cells as early as the neonatal stage is not known, it is well appreciated that both GSK-3 $\beta$ and MEK/ERK signaling are involved in stem cell biology, specifically the regulation of proliferation and maintenance of stem cell identity (56). Interestingly, activation of oncogenic KRas and nuclear GSK-3 $\beta$ using the inducible Rosa26CreERT or Krt19CreERT mice failed to reproduce the IPMN phenotype in KNGC mice, suggesting a differentiation reprogramming in terminal ducts encoded by nuclear GSK$3 \beta$ and oncogenic KRas signaling occurs only during pancreas embryonic development. It is established that Krt19CreERT does not produce Cre recombinase activity in the intercalated/terminal ducts (57), thus future studies using an inducible mouse model to activate Cre in the terminal duct compartment, such as SOX9CreERT are warranted $(48,58)$. 
In summary, our study provides evidence that terminal ducts serve as the cell-of-origin for human IPMN. Future studies using this model combined with the addition of tumor suppressor mutations will be of significant interest as it pertains to IPMN-PDA development. In addition, further characterization of the KNGC mouse model has the potential to identify clinical biomarkers in terminal ducts, which could be used as novel early detection tools for human PDA.

\section{Materials and Methods}

\section{Generation of nuclear GSK-3 $\beta$ conditional knock-in mice and mouse lines.}

Conditional GSK-3ß knock-in mice containing an SV40 nuclear localization sequence (NLS; nGSK-3ß) and HA-tag were generated by the Transgenic and Gene Knockout Mouse Core at the Mayo Clinic according to established protocols (59). The nGSK-3 $\beta$ targeting construct was generated using the previously described Rosa26-targeting vector pR26-CAG/EGFP-Asc, which contains a CAG promoter, and loxP flanked Neo/Stop cassette. LSL-KrasG12D and Pdx1-Cre mice have previously been described $(27,28)$. Pancreas specific overexpression of nuclear GSK-3ß with oncogenic KRas mutation mice was generated by crossing Pdx1-cre/LSL-KRasG12D (KC) mice with LSL-nuclear GSK-3 $\beta$ (NG) mice to produce Pdx1-cre/LSL-KRasG12D/LSL-nuclear GSK-3 $\beta$ (KNGC) animals. Krt19-Cre ${ }^{\text {ERT }}$ mice were obtained from the Jackson Laboratory (Stock Number: 026925). Rosa26-Cre ${ }^{\mathrm{ERT}}$ mice were a gift from Dr. Hu Zeng (Mayo Clinic, MN, USA) and Aqp5 knockout mice were obtained from Dr. Varadaraj Kulandaiappan (Stony Brook University, NY, USA). These lines were intercrossed to obtain the desired genotypes used in this study. The data presented are from mice that 
have been backcrossed onto C57/B6 mice for 6 to 10 generations. Mice were housed in a barrier facility, and all experiments were performed with littermate-matched pairs, both male and female. All procedures were carried out according to the guidelines from and were approved by the Mayo Clinic Institutional Animal Care and Use Committee.

\section{Tamoxifen induction and acute pancreatitis model}

Cre expression and activity was induced in 6-8 week old Krt19-Cre ${ }^{\text {ERT }}$ and Rosa26Cre $^{\text {ERT }}$ mice by intraperitoneal injection of tamoxifen (Sigma) dissolved in corn oil (Sigma) at a dose of $100 \mathrm{mg} / \mathrm{kg}$ of body weight. For mice carrying Krt19-Cre ${ }^{\mathrm{ERT}}$, tamoxifen was injected once a day for 3 days, and for mice carrying Rosa26-Cre ${ }^{\text {ERT }}$, once a day for 5 days. To induce pancreatitis, 6-8 week old sibling littermates from Pdx1-cre (WT) and Pdx1-cre/nuclear GSK-3ß (NGC) were selected for treatment. Mice were fasted for $12 \mathrm{~h}$ and allowed water ad libitum one day prior to the experiment. Animals were injected intraperitoneally into the right lower quadrant with a $50 \mu \mathrm{g} / \mathrm{kg} / \mathrm{bw}$ (body weight) of caerulein dissolved in $0.9 \%$ saline in a volume of $100 \mu$ l. Injections were given at hourly intervals up to 8 times. Pancreata were harvested 7 days after caerulein treatment.

\section{Pancreatic ductal cell isolation}

Preparation of single-cell suspensions from the mouse pancreas and pancreatic ductal cell isolation was performed as described $(37,38,60)$. Briefly, mouse pancreata were removed and soaked overnight in cold $0.25 \%$ trypsin-EDTA (Thermofisher Scientific). The upper enzymatic fluid was aspirated and the digestion was continued for 10 min at $37^{\circ} \mathrm{C}$ with residual trypsin-EDTA and DNase I (Sigma, $10 \mu \mathrm{g} / \mathrm{ml}$ ) in $3 \mathrm{ml}$ of DMEM/F12 
medium (Thermofisher Scientific). The pancreas tissue was further digested in DMEM/F12 supplemented with collagenase D (Sigma, $2.5 \mathrm{mg} / \mathrm{ml}$ ) and liberase DL (Sigma, $0.5 \mathrm{mg} / \mathrm{ml}$ ), and DNase I for $10 \mathrm{~min}$ at $37^{\circ} \mathrm{C}$ with gentle shaking. The digestion was terminated and quenched by excess DMEM/F12 supplemented with 1X GlutaMAX (Gibco), $10 \mathrm{mmol} / \mathrm{L}$ HEPES (Gibco), and $1 \%$ of penicillin/streptomycin (Gibco). Cells were gently pipetted to maximize the release of single cells and spun down, and resuspended in ACK lysis buffer to eliminate red blood cells. ACK buffer was quenched with $2 \%$ fetal bovine serum (FBS) in PBS and cells were resuspended in a sorting buffer containing PBS, $0.5 \%$ bovine serum albumin, and $2 \mathrm{mM}$ EDTA, followed by $10 \mathrm{~min}$ incubation in fluorescein-labeled Dolichos biflorus agglutinin (DBA) lectin (Vector Laboratories) with agitation at $4^{\circ} \mathrm{C}$. Cells were washed in the sorting buffer and resuspended in the same buffer with anti-FITC Microbeads (Miltenyi Biotec), and incubated on a rotor for $15 \mathrm{~min}$ at $4^{\circ} \mathrm{C}$. Separation was performed using MS columns (Miltenyi Biotec), according to the manufacturer's protocol.

\section{Immunoblot Analysis}

Collected pancreata or isolated pancreatic ductal cells were lysed with Western lysis buffer (1\% Triton X-100, 10 mM Tris Base, 50 mM NaCl, 5 mM EDTA, 50 mM NaF, 30 mM Na4P2O7 pH 7.4) supplemented with aprotinin, leupeptin, sodium orthovanadate, phenylmethylsulfonyl fluoride (PMSF) and calyculin A (Cell Signaling Technologies, Beverly, MA, USA). Lysates were subjected to sodium dodecyl sulfate (SDS)polyacrylamide gel electrophoresis and immunoblotting as described (27). Antibodies used for immunoblotting and immunofluorescence are described in detail in Supplemental Excel Table S1. 


\section{IHC, EdU labeling and Immunofluorescence (IF)}

Mice were anesthetized using isoflurane (Nova Plus Pharmaceuticals), followed by cervical dislocation. The whole pancreas was quickly removed and fixed overnight in $4 \%$ PFA with gentle shaking, embedded in paraffin, cut into $5 \mu \mathrm{m}$-thick sections. Sections were subjected to $\mathrm{H \& E}, \mathrm{IHC}$ and immunofluorescence staining as described (27). Briefly, sections were de-paraffinized and hydrated by graded washes with xylene and ethanol. Antigen retrieval was accomplished by sub-boiling in $10 \mathrm{mM}$ sodium citrate acid buffer (pH 6.0) for 15 min. Endogenous peroxidase activity was blocked by incubation of slides in $3 \% \mathrm{H}_{2} \mathrm{O}_{2}$ for 10 min. Nonspecific binding was blocked with $5 \%$ normal goat serum. Sections were then incubated with primary antibodies overnight at $4^{\circ} \mathrm{C}$. Anti-rabbit secondary (\#8114, Cell Signaling Technologies, Beverly, MA, USA) and diaminobenzidine substrate kit (\#8059, Cell Signaling Technologies, Beverly, MA, USA) were used for immunohistochemistry. Slides were then counterstained with Mayer's Hematoxylin before dehydration and mounting. For immunofluorescence, slides were incubated with fluorescent-conjugated secondary antibodies for $1 \mathrm{~h}$ at room temperature before confocal scanning. For EdU labeling, mice were injected with EdU at a concentration of $50 \mathrm{mg} / \mathrm{kg} / \mathrm{bw}$ in saline 2 hours before sacrifice. Staining was performed by Click-iT® EdU Alexa Fluor® 647 Imaging Kit following manufacturer's instructions (Thermofisher scientific, USA). Confocal images were collected with an LSM-800 laser scanning confocal microscope with a 63x-oil Plan-Apochromat objective lens using ZEN Blue 2.6 software package (Carl Zeiss, Oberkochen, Germany). For whole pancreas tissue section scanning, stage marks were placed around the edge of the pancreas and tile region was drawn to cover all the stage marks. Images were taken under 10x 
objective lens using tiles. The stitching method within the Zen Blue software package was applied to process the tile images into one final image. The percentage of EdU-647 + cells was enumerated, and the area and integrated density of indicated staining were measured using the ImageJ open source image-processing package.

\section{RNA isolation and quantitative RT-PCR}

RNA isolation and quantitative RT-PCR were performed as previously described (27). Briefly, pancreatic total RNA or isolated pancreatic ductal cells was isolated using Trizol and further purified with an RNeasy Mini Kit (Qiagen, Valencia, CA). Reverse transcription was performed with the Superscript III RT-PCR Kit (Invitrogen). Quantitative PCR was performed with the SYBR Green PCR Master Mix using the ABI StepOnePlus Sequence Detection System (Applied Biosystems, Carlsbad, CA). Four housekeeping genes were used for normalization of gene expression. The double $\Delta \mathrm{Ct}$ method was used to analyze gene expression. Experiments were performed a minimum of three times using independent cDNAs. Primer sequences are provided in Supplemental Excel Table S2.

\section{RNA-Seq and data analysis}

Total RNA was isolated from 4 weeks old littermates as described above and the average RNA integrity number values were measured by an Agilent Bioanalyzer. Individual transcriptome sequencing (RNA-Seq) libraries were prepared from each mouse using an Illumina TruSeq v2 kit. 100 base pairs reads were collected with an Illumina HiSeq 4000 instrument. Fastq files of paired-end reads were aligned with STAR 2.6.0a (61) to the UCSC reference genome mm10 with basic 2-pass mapping. Gene 
counts were obtained using the subRead featureCounts program 1.4.6 (62) based on the UCSC mm10 annotation. Differential expression analyses were performed using R package DESeq2 1.10.1 (63) after removing genes with average raw counts less than 10. Genes with $\log 2$ fold change greater than 2 or less than -2 , and FDR less than 0.05 were considered significantly differentially expressed. For functional annotation analysis, the Fisher's exact test was used to determine overrepresented pathways or gene sets in significantly up- or down-regulated genes, against gene sets described in Enrichment Map (64) and R package KEGG.db (65). RNA sequencing data have been deposited in the Gene Expression Omnibus under the accession number GSE153548.

\section{Staining on Tissue Microarrays}

The tissue microarrays (TMAs) consisted of 140 unique individuals with IPMN who were acquired from the Mayo Clinic SPORE in Pancreatic Cancer. IHC for Aqp5 and immunofluorescence staining of Agr2/DBA/CK19 were performed as above. Cores were excluded if absent in the slide. Aqp5 histological scoring was performed and evaluated by pathologist (Lizhi Zhang) as follows, staining intensities were scored from 0 (no staining) to 3 (high staining) and extent was scored from 0 (negative), $1(<25 \%), 2$ (25$50 \%), 3(50-75 \%)$, to $4(>75 \%$, widespread staining). Whole slides scanning and measurement of intensity and area of Agr2/DBA/CK19 immunofluorescence staining in TMAs were described above and staining intensities were scored from weak $(<33 \%)$, medium $(33-66 \%)$ to strong $(>66 \%)$ and extent was scored as the percentage of Agr2/DBA in CK19 positive cells. The $\mathrm{H}$-score system was used for IHC evaluation of Aqp5 and IF evaluation of Agr2 and DBA by multiplying the extend or percentage of 
cells with staining intensity ordinal value ranging from 0 to 300 . $\mathrm{H}$-scores were available on 133 to 135 of the 140 patients represented on the TMA.

\section{Statistical analysis}

Data are expressed as mean \pm SEM and analyzed by repeated measures analysis of variance, one-way ANOVA and unpaired Student's t-test using GraphPad Prism software (GraphPad Software Inc., La Jolla, CA). A value of $p<0.05$ denotes statistical significance. Scatterplots including a loess smoother (smoothing parameter=0.8) were generated to visualize the relationship between AGR2 and AQP5. Spearman correlation coefficient and p-value are reported to summarize the nature of the relationship. 


\section{Acknowledgement}

We would like to thank members of the Division of Oncology Research especially Drs.

Scott Kaufmann, Zhenkun Lou, Martin Fernandez-Zapico as well as members of the Billadeau laboratory for helpful discussions. We would like to thank Dr. Varadaraj Kulandaiappan (Stony Brook University, NY, USA) for the Aqp5 knockout mice. Lastly, we would like to thank Dr. Howard Crawford and other members of the Cold Spring Harbor Pancreatic Cancer Workshop - for thought-provoking discussions that helped shape this project. 


\section{References}

1. Garrido-Laguna I, Hidalgo M. Pancreatic cancer: from state-of-the-art treatments to promising novel therapies. Nat Rev Clin Oncol 2015;12(6):319-34 doi 10.1038/nrclinonc.2015.53.

2. Rahib L, Smith BD, Aizenberg R, Rosenzweig AB, Fleshman JM, Matrisian LM. Projecting cancer incidence and deaths to 2030: the unexpected burden of thyroid, liver, and pancreas cancers in the United States. Cancer Res 2014;74(11):2913-21 doi 10.1158/0008-5472.CAN-14-0155.

3. Society AC. Cancer Facts \& Figures 2019. Atlanta: American Cancer Society2019.

4. Blackford AL, Canto MI, Klein AP, Hruban RH, Goggins M. Recent trends in the incidence and survival of Stage 1A Pancreatic Cancer: A Surveillance, Epidemiology, and End Results analysis. J Natl Cancer Inst 2020 doi 10.1093/jnci/djaa004.

5. Pihlak R, Valle JW, McNamara MG. Germline mutations in pancreatic cancer and potential new therapeutic options. Oncotarget 2017;8(42):73240-57 doi 10.18632/oncotarget.17291.

6. Singhi AD, \& Maitra, A. The molecular pathology of precursor lesions of pancreatic cancer. In Pancreatic Cancer (pp. 147-176): Springer New York. https://doi.org/10.1007/978-1-4939-7193$\underline{0}$ 5; 2018. 147-76 p.

7. Matthaei H, Schulick RD, Hruban RH, Maitra A. Cystic precursors to invasive pancreatic cancer. Nat Rev Gastroenterol Hepatol 2011;8(3):141-50 doi 10.1038/nrgastro.2011.2.

8. Bardeesy N, DePinho RA. Pancreatic cancer biology and genetics. Nat Rev Cancer 2002;2(12):897-909 doi 10.1038/nrc949.

9. Reichert M, Rustgi AK. Pancreatic ductal cells in development, regeneration, and neoplasia. J Clin Invest 2011;121(12):4572-8 doi 10.1172/JCI57131.

10. Storz P, Crawford HC. Carcinogenesis of Pancreatic Ductal Adenocarcinoma. Gastroenterology 2020 doi 10.1053/j.gastro.2020.02.059.

11. Morris JPt, Wang SC, Hebrok M. KRAS, Hedgehog, Wnt and the twisted developmental biology of pancreatic ductal adenocarcinoma. Nat Rev Cancer 2010;10(10):683-95 doi 10.1038/nrc2899.

12. Kanda M, Matthaei $\mathrm{H}, \mathrm{Wu} J$, Hong SM, Yu J, Borges $M$, et al. Presence of somatic mutations in most early-stage pancreatic intraepithelial neoplasia. Gastroenterology 2012;142(4):730-33 e9 doi 10.1053/j.gastro.2011.12.042.

13. Patra KC, Bardeesy N, Mizukami Y. Diversity of Precursor Lesions For Pancreatic Cancer: The Genetics and Biology of Intraductal Papillary Mucinous Neoplasm. Clin Transl Gastroenterol 2017;8(4):e86 doi 10.1038/ctg.2017.3.

14. Storz P. Acinar cell plasticity and development of pancreatic ductal adenocarcinoma. Nat Rev Gastroenterol Hepatol 2017;14(5):296-304 doi 10.1038/nrgastro.2017.12.

15. Mazur PK, Siveke JT. Genetically engineered mouse models of pancreatic cancer: unravelling tumour biology and progressing translational oncology. Gut 2012;61(10):1488-500 doi 10.1136/gutjnl-2011-300756.

16. Xu Y, Liu J, Nipper M, Wang P. Ductal vs. acinar? Recent insights into identifying cell lineage of pancreatic ductal adenocarcinoma. Ann Pancreat Cancer 2019;2 doi 10.21037/apc.2019.06.03.

17. Woodgett JR. Molecular cloning and expression of glycogen synthase kinase-3/factor A. EMBO J 1990;9(8):2431-8.

18. Cormier KW, Woodgett JR. Recent advances in understanding the cellular roles of GSK-3. F1000Res 2017;6 doi 10.12688/f1000research.10557.1.

19. Kaidanovich-Beilin O, Woodgett JR. GSK-3: Functional Insights from Cell Biology and Animal Models. Front Mol Neurosci 2011;4:40 doi 10.3389/fnmol.2011.00040.

20. Walz A, Ugolkov A, Chandra S, Kozikowski A, Carneiro BA, O'Halloran TV, et al. Molecular Pathways: Revisiting Glycogen Synthase Kinase-3beta as a Target for the Treatment of Cancer. Clin Cancer Res 2017;23(8):1891-97 doi 10.1158/1078-0432.CCR-15-2240. 
21. Beurel E, Grieco SF, Jope RS. Glycogen synthase kinase-3 (GSK3): regulation, actions, and diseases. Pharmacol Ther 2015;148:114-31 doi 10.1016/j.pharmthera.2014.11.016.

22. McCubrey JA, Steelman LS, Bertrand FE, Davis NM, Sokolosky M, Abrams SL, et al. GSK-3 as potential target for therapeutic intervention in cancer. Oncotarget 2014;5(10):2881-911 doi 10.18632/oncotarget.2037.

23. Ding L, Billadeau DD. Glycogen synthase kinase-3beta: a novel therapeutic target for pancreatic cancer. Expert Opin Ther Targets 2020;24(5):417-26 doi 10.1080/14728222.2020.1743681.

24. Ougolkov AV, Fernandez-Zapico ME, Bilim VN, Smyrk TC, Chari ST, Billadeau DD. Aberrant nuclear accumulation of glycogen synthase kinase-3beta in human pancreatic cancer: association with kinase activity and tumor dedifferentiation. Clin Cancer Res 2006;12(17):507481 doi 10.1158/1078-0432.CCR-06-0196.

25. Xie Y, Zhu S, Zhong M, Yang M, Sun X, Liu J, et al. Inhibition of Aurora Kinase A Induces Necroptosis in Pancreatic Carcinoma. Gastroenterology 2017;153(5):1429-43 e5 doi 10.1053/j.gastro.2017.07.036.

26. Zhang JS, Koenig A, Harrison A, Ugolkov AV, Fernandez-Zapico ME, Couch FJ, et al. Mutant K-Ras increases GSK-3beta gene expression via an ETS-p300 transcriptional complex in pancreatic cancer. Oncogene 2011;30(34):3705-15 doi 10.1038/onc.2011.90.

27. Ding L, Liou GY, Schmitt DM, Storz P, Zhang JS, Billadeau DD. Glycogen synthase kinase-3beta ablation limits pancreatitis-induced acinar-to-ductal metaplasia. J Pathol 2017;243(1):65-77 doi 10.1002/path.4928.

28. Hingorani SR, Petricoin EF, Maitra A, Rajapakse V, King C, Jacobetz MA, et al. Preinvasive and invasive ductal pancreatic cancer and its early detection in the mouse. Cancer Cell 2003;4(6):437-50.

29. Hingorani SR, Wang L, Multani AS, Combs C, Deramaudt TB, Hruban RH, et al. Trp53R172H and KrasG12D cooperate to promote chromosomal instability and widely metastatic pancreatic ductal adenocarcinoma in mice. Cancer Cell 2005;7(5):469-83 doi 10.1016/j.ccr.2005.04.023.

30. Aguirre AJ, Bardeesy N, Sinha M, Lopez L, Tuveson DA, Horner J, et al. Activated Kras and Ink4a/Arf deficiency cooperate to produce metastatic pancreatic ductal adenocarcinoma. Genes Dev 2003;17(24):3112-26 doi 10.1101/gad.1158703.

31. Carriere C, Young AL, Gunn JR, Longnecker DS, Korc M. Acute pancreatitis markedly accelerates pancreatic cancer progression in mice expressing oncogenic Kras. Biochem Biophys Res Commun 2009;382(3):561-5 doi 10.1016/j.bbrc.2009.03.068.

32. Gidekel Friedlander SY, Chu GC, Snyder EL, Girnius N, Dibelius G, Crowley D, et al. Contextdependent transformation of adult pancreatic cells by oncogenic K-Ras. Cancer Cell 2009;16(5):379-89 doi 10.1016/j.ccr.2009.09.027.

33. Song SY, Gannon M, Washington MK, Scoggins CR, Meszoely IM, Goldenring JR, et al. Expansion of Pdx1-expressing pancreatic epithelium and islet neogenesis in transgenic mice overexpressing transforming growth factor alpha. Gastroenterology 1999;117(6):1416-26 doi 10.1016/s00165085(99)70292-1.

34. Kim SK, MacDonald RJ. Signaling and transcriptional control of pancreatic organogenesis. Curr Opin Genet Dev 2002;12(5):540-7 doi 10.1016/s0959-437x(02)00338-6.

35. Hoang CQ, Hale MA, Azevedo-Pouly AC, Elsasser HP, Deering TG, Willet SG, et al. Transcriptional Maintenance of Pancreatic Acinar Identity, Differentiation, and Homeostasis by PTF1A. Mol Cell Biol 2016;36(24):3033-47 doi 10.1128/MCB.00358-16.

36. Muraro MJ, Dharmadhikari G, Grun D, Groen N, Dielen T, Jansen E, et al. A Single-Cell Transcriptome Atlas of the Human Pancreas. Cell Syst 2016;3(4):385-94 e3 doi 10.1016/j.cels.2016.09.002. 
37. Reichert M, Takano S, Heeg S, Bakir B, Botta GP, Rustgi AK. Isolation, culture and genetic manipulation of mouse pancreatic ductal cells. Nat Protoc 2013;8(7):1354-65 doi 10.1038/nprot.2013.079.

38. Elyada E, Bolisetty M, Laise P, Flynn WF, Courtois ET, Burkhart RA, et al. Cross-Species Single-Cell Analysis of Pancreatic Ductal Adenocarcinoma Reveals Antigen-Presenting Cancer-Associated Fibroblasts. Cancer Discov 2019;9(8):1102-23 doi 10.1158/2159-8290.CD-19-0094.

39. Ramachandran V, Arumugam T, Wang H, Logsdon CD. Anterior gradient 2 is expressed and secreted during the development of pancreatic cancer and promotes cancer cell survival. Cancer Res 2008;68(19):7811-8 doi 10.1158/0008-5472.CAN-08-1320.

40. Direito I, Paulino J, Vigia E, Brito MA, Soveral G. Differential expression of aquaporin-3 and aquaporin-5 in pancreatic ductal adenocarcinoma. J Surg Oncol 2017;115(8):980-96 doi $10.1002 / \mathrm{jso} .24605$.

41. Ferreira RMM, Sancho R, Messal HA, Nye E, Spencer-Dene B, Stone RK, et al. Duct- and AcinarDerived Pancreatic Ductal Adenocarcinomas Show Distinct Tumor Progression and Marker Expression. Cell Rep 2017;21(4):966-78 doi 10.1016/j.celrep.2017.09.093.

42. Burghardt B, Elkaer ML, Kwon TH, Racz GZ, Varga G, Steward MC, et al. Distribution of aquaporin water channels AQP1 and AQP5 in the ductal system of the human pancreas. Gut 2003;52(7):1008-16 doi 10.1136/gut.52.7.1008.

43. Reichert M, Takano S, von Burstin J, Kim SB, Lee JS, Ihida-Stansbury K, et al. The Prrx1 homeodomain transcription factor plays a central role in pancreatic regeneration and carcinogenesis. Genes Dev 2013;27(3):288-300 doi 10.1101/gad.204453.112.

44. Norris AM, Gore A, Balboni A, Young A, Longnecker DS, Korc M. AGR2 is a SMAD4-suppressible gene that modulates MUC1 levels and promotes the initiation and progression of pancreatic intraepithelial neoplasia. Oncogene 2013;32(33):3867-76 doi 10.1038/onc.2012.394.

45. Dumartin L, Alrawashdeh W, Trabulo SM, Radon TP, Steiger K, Feakins RM, et al. ER stress protein AGR2 precedes and is involved in the regulation of pancreatic cancer initiation. Oncogene 2017;36(22):3094-103 doi 10.1038/onc.2016.459.

46. Arumugam T, Deng D, Bover L, Wang H, Logsdon CD, Ramachandran V. New Blocking Antibodies against Novel AGR2-C4.4A Pathway Reduce Growth and Metastasis of Pancreatic Tumors and Increase Survival in Mice. Mol Cancer Ther 2015;14(4):941-51 doi 10.1158/1535-7163.MCT-140470.

47. Mendez-Gimenez L, Ezquerro S, da Silva IV, Soveral G, Fruhbeck G, Rodriguez A. Pancreatic Aquaporin-7: A Novel Target for Anti-diabetic Drugs? Front Chem 2018;6:99 doi 10.3389/fchem.2018.00099.

48. Nakano Y, Negishi N, Gocho S, Mine T, Sakurai Y, Yazawa M, et al. Disappearance of centroacinar cells in the Notch ligand-deficient pancreas. Genes Cells 2015;20(6):500-11 doi 10.1111/gtc.12243.

49. Krane CM, Melvin JE, Nguyen HV, Richardson L, Towne JE, Doetschman T, et al. Salivary acinar cells from aquaporin 5-deficient mice have decreased membrane water permeability and altered cell volume regulation. J Biol Chem 2001;276(26):23413-20 doi 10.1074/jbc.M008760200.

50. Whitcomb DC, LaRusch J, Krasinskas AM, Klei L, Smith JP, Brand RE, et al. Common genetic variants in the CLDN2 and PRSS1-PRSS2 loci alter risk for alcohol-related and sporadic pancreatitis. Nat Genet 2012;44(12):1349-54 doi 10.1038/ng.2466.

51. Patra KC, Kato Y, Mizukami Y, Widholz S, Boukhali M, Revenco I, et al. Mutant GNAS drives pancreatic tumourigenesis by inducing PKA-mediated SIK suppression and reprogramming lipid metabolism. Nat Cell Biol 2018;20(7):811-22 doi 10.1038/s41556-018-0122-3. 
52. Hezel AF, Kimmelman AC, Stanger BZ, Bardeesy N, Depinho RA. Genetics and biology of pancreatic ductal adenocarcinoma. Genes Dev 2006;20(10):1218-49 doi 10.1101/gad.1415606.

53. Taki K, Ohmuraya M, Tanji E, Komatsu H, Hashimoto D, Semba K, et al. GNAS(R201H) and $\operatorname{Kras}(\mathrm{G12D})$ cooperate to promote murine pancreatic tumorigenesis recapitulating human intraductal papillary mucinous neoplasm. Oncogene 2016;35(18):2407-12 doi 10.1038/onc.2015.294.

54. von Figura G, Fukuda A, Roy N, Liku ME, Morris Iv JP, Kim GE, et al. The chromatin regulator Brg1 suppresses formation of intraductal papillary mucinous neoplasm and pancreatic ductal adenocarcinoma. Nat Cell Biol 2014;16(3):255-67 doi 10.1038/ncb2916.

55. Roy N, Malik S, Villanueva KE, Urano A, Lu X, Von Figura G, et al. Brg1 promotes both tumorsuppressive and oncogenic activities at distinct stages of pancreatic cancer formation. Genes Dev 2015;29(6):658-71 doi 10.1101/gad.256628.114.

56. Fitzgerald TL, Lertpiriyapong K, Cocco L, Martelli AM, Libra M, Candido S, et al. Roles of EGFR and KRAS and their downstream signaling pathways in pancreatic cancer and pancreatic cancer stem cells. Adv Biol Regul 2015;59:65-81 doi 10.1016/j.jbior.2015.06.003.

57. Ray KC, Bell KM, Yan J, Gu G, Chung CH, Washington MK, et al. Epithelial tissues have varying degrees of susceptibility to $\mathrm{Kras}(\mathrm{G} 12 \mathrm{D})$-initiated tumorigenesis in a mouse model. Plos One 2011;6(2):e16786 doi 10.1371/journal.pone.0016786.

58. Kopp JL, Dubois CL, Schaffer AE, Hao E, Shih HP, Seymour PA, et al. Sox9+ ductal cells are multipotent progenitors throughout development but do not produce new endocrine cells in the normal or injured adult pancreas. Development 2011;138(4):653-65 doi 10.1242/dev.056499.

59. Dawlaty MM, van Deursen JM. Gene targeting methods for studying nuclear transport factors in mice. Methods 2006;39(4):370-8 doi 10.1016/j.ymeth.2006.06.009.

60. Li D, Peng SY, Zhang ZW, Feng RC, Li L, Liang J, et al. Complete disassociation of adult pancreas into viable single cells through cold trypsin-EDTA digestion. J Zhejiang Univ Sci B 2013;14(7):596603 doi 10.1631/jzus.B1200226.

61. Dobin A, Davis CA, Schlesinger F, Drenkow J, Zaleski C, Jha S, et al. STAR: ultrafast universal RNAseq aligner. Bioinformatics 2013;29(1):15-21 doi 10.1093/bioinformatics/bts635.

62. Liao Y, Smyth GK, Shi W. featureCounts: an efficient general purpose program for assigning sequence reads to genomic features. Bioinformatics 2014;30(7):923-30 doi 10.1093/bioinformatics/btt656.

63. Love MI, Huber W, Anders S. Moderated estimation of fold change and dispersion for RNA-seq data with DESeq2. Genome Biol 2014;15(12):550 doi 10.1186/s13059-014-0550-8.

64. Merico D, Isserlin R, Stueker O, Emili A, Bader GD. Enrichment map: a network-based method for gene-set enrichment visualization and interpretation. Plos One 2010;5(11):e13984 doi 10.1371/journal.pone.0013984.

65. M C. KEGG.db: A set of annotation maps for KEGG. R package version 3232016. 


\section{Figure legend}

Figure 1. GSK-3ß deletion limits oncogenic KRas-induced pancreatic cancer development. (A) Scheme for aging-induced pancreatic cancer progression model and analysis. (B) Immunofluorescence staining of GSK-3ß (red) and CK19 (green) from pancreatic sections of aging KC and RKO mice. Nuclei were counter-stained with Hoechst (blue). (C) H\&E stained pancreatic sections from KC and RKO mice. Black boxes indicate magnified area. (D) H\&E stained tissue samples from KC and RKO mice were evaluated and quantitatively analyzed for numbers per $100 \mathrm{~mm}^{2}$. Data were analyzed and expressed as mean \pm SEM. ${ }^{*} \mathrm{P}<0.05 \mathrm{RKO}$ versus $\mathrm{KC}$ mice. (E) Doublelabeling of pancreatic sections from aging $\mathrm{KC}$ and $\mathrm{RKO}$ mice was performed using incorporated EdU detection kit (red) and CK19 (green) antibodies. Nuclei were counterstained with Hoechst (blue). (F) Quantification of the percentage of EdU positive neoplastic ductal cells in aging KC and RKO mice. Data were analyzed and expressed as mean \pm SEM. $n=6 .{ }^{*} P<0.05 R K O$ versus $K C$ mice.

Figure 2. Nuclear GSK-3 $\beta$ and oncogenic KRas promote pancreatic ductal cell expansion and IPMN development. (A) Schematic representation of KNGC (LSLKRasG12D/Rosa26-LSL-nuclear GSK-3ß/Pdx1-Cre) mouse model. Cre expression is driven by the Pdx1 promoter-Cre transgene. Blue triangles indicate loxP sites. (B) Cell lysates from the indicated genotypes at 4 weeks of age were prepared and probed with the indicated antibodies. $\beta$-actin was used as a loading control. Shown are representative results from 6 experiments. (C) Gross pathology of pancreas and 
adjacent tissues from transgenic mice of indicated genotypes at 4 weeks of age. (D) Immunofluorescence staining of HA-tag (red), aSMA (green) and CK19 (purple) from pancreatic sections of the indicated genotypes at 4 weeks of age. Nuclei were counterstained with Hoechst (blue). Body weight (E) and area under the curve (AUC) (F) of WT, NGC, KC and KNGC mice fed normal chow diet were measured at the indicated time points. Data were analyzed and expressed as mean \pm SEM. At least 10 mice were included at each point. ${ }^{*} \mathrm{P}<0.05 \mathrm{KNGC}$ mice versus the other genotypes. (G) KaplanMeier survival curve of the indicated genotypes. $(H) H \& E$ stained pancreatic sections from KNGC mice of 4 weeks, 4 months and 8 months. Black boxes indicate magnified area. Quantification of pancreatic duct size distribution (I) and distribution of pancreatic duct size $(\mathrm{J})$ for KNGC mice were analyzed and expressed as mean \pm SEM. $\mathrm{n}=5$. ${ }^{\star} \mathrm{P}<0.054$ months versus 4 weeks $\mathrm{KNGC}$ mice. $\# \mathrm{P}<0.058$ months versus 4 months KNGC mice.

Figure 3. Nuclear GSK-3 $\beta$ and oncogenic KRas initiate ductal hyperplasia at an early stage of pancreas development. (A) Schematic representation of NG-, K- or KNG-R26CreER (LSL-KRasG12D/Rosa26-LSL-nuclearGSK-3ß/Rosa26-Cre ${ }^{\text {ERT }}$ ) mouse model. Cre expression under the Rosa26 promoter was induced by tamoxifen injection in 6-8-week old mice. Blue triangles indicate loxP sites. (B) Cell lysates from pancreas of indicated genotypes 28 days post tamoxifen injection were prepared and probed with the indicated antibodies. Tubulin, $\beta$-actin and GAPDH were used as a loading control. Shown are representative results from 5 experiments. (C) H\&E and immunofluorescence staining of HA-tag (red) and CK19 (green) pancreatic sections 
from K-R26CreER and KNG-R26CreER mice treated as above. Black boxes indicated area magnified. Nuclei were counter-stained with Hoechst (blue). (D) Schematic representation of K- or KNG-Krt19CreER (LSL-KRasG12D/Rosa26-LSL-nuclear GSK$3 \beta / K_{r t 19-C r e}{ }^{\text {ERT }}$ ) mouse model. Cre expression under the Krt19 promoter was induced by tamoxifen injection in 6-8-week old mice. Blue triangles indicate loxP sites. (E) H\&E stained pancreatic sections from K-Krt19CreER and KNG-Krt19CreER mice treated as above. Black boxes indicate magnified area. (F) H\&E stained pancreatic sections from neonatal KC and KNGC mice. Black boxes indicate magnified area. (G) Pancreas section of neonatal KNGC mice in (F) were stained for pS10HH3 (red) and CK19 (green). White boxes indicate magnified area. Nuclei were counter-stained with Hoechst (blue). Quantification of average pancreatic duct size $(H)$, pancreatic duct size distribution (I) as well as number of ducts per $10^{-4} \mu \mathrm{m}^{2}(\mathrm{~J})$ and percentage of $\mathrm{pS} 10 \mathrm{HH} 3$ positive ducts $(K)$ were analyzed and expressed as mean \pm SEM. $n=4$. ${ }^{*} P<0.05$ KNGC mice versus the other genotypes.

Figure 4. Transcriptional regulation of pancreatic ductal neoplasia by nuclear GSK-3 $\beta$ and oncogenic KrasG12D. (A) KEGG cellular processes enriched for genes with increased expression in KNGC mice compared with NGC or KC. (B) KEGG cellular processes enriched for genes with decreased expression in KNGC mice compared with NGC or KC. (C) and (D) Heatmap was generated for selected gene sets related to the indicated groups using normalized gene expression. Colors are assigned based on raw z-scores. (E) Real-time PCR quantification of the indicated genes from 4-week old WT, NGC, KC or KNGC mice. TBP, $\beta$-actin, RPLPO and GAPDH were used as internal 
housekeeping gene controls. Data were analyzed and expressed as mean \pm SEM. $n=3$. ${ }^{*} \mathrm{P}<0.05 \mathrm{KNGC}$ mice versus the other genotypes. $(\mathrm{F})$ Cell lysates from pancreas of 4 week WT, NGC, KC and KNGC mice were prepared and probed with the indicated antibodies. Tubulin, $\beta$-actin and GAPDH were used as a loading control. Shown are representative results from 3 experiments. (G) Immunofluorescence staining of CK19 (red) and Amylase (green) from pancreatic sections of 4-week old KNGC mice. White boxes indicate magnified area. Nuclei were counter-stained with Hoechst (blue). $(\mathrm{H})$ Quantification of percentage of total pancreas area and integrated density were analyzed and expressed as mean \pm SEM. ${ }^{*} \mathrm{P}<0.05 \mathrm{KNGC}$ mice versus the other genotypes. (I) Immunofluorescence staining of Agr2 (red) and CK19 (green) from pancreatic sections of 4-week old KNGC mice. White arrow indicated Agr2 negative/CK19 positive cells. Nuclei were counter-stained with Hoechst (blue). (J) Quantification of Agr2 positive percentage in CK19 cells was analyzed and expressed as mean \pm SEM. ${ }^{*} \mathrm{P}<0.05$ KNGC mice versus the other genotypes. (K) Immunofluorescence staining of Aqp5 (red) and CK19 (green) from pancreatic sections of 4-week old WT, NGC, KC and KNGC mice. Nuclei were counter-stained with Hoechst (blue). (L) Quantification of Aqp5 positive percentage in CK19 cells and integrated density were analyzed and expressed as mean \pm SEM. ${ }^{*} \mathrm{P}<0.05 \mathrm{KNGC}$ mice versus the other genotypes. 
Figure 5. KNGC mice develop two distinct ductal populations. (A) Illustration of the experimental approach to purify lectin-expressing ductal cells that can be enriched through binding of DBA. (B) Cell lysates from isolated DBA negative and positive cells of two individual 4 week old KNGC mice were prepared and probed with the indicated antibodies. Tubulin, $\beta$-actin and GAPDH were used as a loading control. Shown are representative results from 3 experiments. (C) The average signal intensity of Agr2 and pan-Keratin was quantified and expressed as mean \pm SEM. $n=3 .{ }^{*} P<0.05$ DBA negative versus DBA positive samples. (D) Real-time PCR quantification of the indicated genes from isolated DBA negative and positive samples from aging $\mathrm{KC}$ and 4 week old $\mathrm{KNGC}$ mice. TBP, $\beta$-actin, RPLPO and GAPDH were used as internal housekeeping gene controls. Data were analyzed and expressed as mean \pm SEM. $n=3 .{ }^{*} P<0.05$ DBA positive versus $\mathrm{DBA}$ negative samples of aging $\mathrm{KC}$ mice. $\# \mathrm{P}<0.05 \mathrm{DBA}$ negative from KNGC versus DBA negative from aging $\mathrm{KC}$ mice. $\$ \mathrm{P}<0.05 \mathrm{DBA}$ negative versus $\mathrm{DBA}$ positive samples of KNGC mice. (E) Immunofluorescence staining of Agr2 (red, upper panel) or Aqp5 (red, lower panel) with DBA-FITC (green) from pancreatic sections of 4week old KNGC mice. Nuclei were counter-stained with Hoechst (blue). (F) Immunofluorescence staining of EdU (white), Agr2 (red) and DBA-FITC (green) from pancreatic sections of 4-week old KNGC mice. Nuclei were counter-stained with Hoechst (blue). (G) Quantification of EdU positive percentage in Agr2 positive or DBAFITC positive cells was analyzed and expressed as mean \pm SEM. ${ }^{*} \mathrm{P}<0.05$ EdU positive in Agr2 positive versus DBA-FITC positive cells. 
Figure 6. Aqp5 is necessary for the differentiation and growth of terminal ducts in KNGC mice. (A) Schematic representation of KNGCA (LSL-KRasG12D/Rosa26-LSLnuclear GSK-3ß/Pdx1-Cre/Aqp5 knockout) mouse model. Blue triangles indicate loxP sites. Black rectangles indicate exons of aqp5 gene. (B) Real-time PCR quantification of Aqp5 gene expression from 4-week old KNGC and KNGCA mice. TBP, $\beta$-actin, RPLP0 and GAPDH were used as internal housekeeping gene controls. Data were analyzed and expressed as mean \pm SEM. ${ }^{*} \mathrm{P}<0.05 \mathrm{KNGCA}$ versus KNGC mice. (C) Immunofluorescence staining of Aqp5 (red), DBA-FITC (green) and CK19 (purple) from pancreatic sections of 4-week old KNGC and KNGCA mice. Nuclei were counterstained with Hoechst (blue). (D) H\&E stained pancreatic sections from KNGC and KNGCA mice. Black boxes indicated area magnified. (E) Quantification of pancreatic ducts size distribution and average pancreatic duct size were analyzed and expressed as mean \pm SEM. $n=3 .{ }^{*} \mathrm{P}<0.05 \mathrm{KNGCA}$ versus $\mathrm{KNGC}$ mice. (F) Real-time PCR quantification of the indicated genes expressions from 4-week old KNGC and KNGCA mice. TBP, $\beta$-actin, RPLP0 and GAPDH were used as internal housekeeping gene controls. Data were analyzed and expressed as mean \pm SEM. ${ }^{*} \mathrm{P}<0.05$ KNGCA versus KNGC mice. (G) Immunofluorescence staining of Agr2 (red, upper panel) or pS10HH3 (red, lower panel) with DBA-FITC (green) and CK19 (purple) from serial pancreatic sections of 4-week old KNGC and KNGCA mice. Nuclei were counter-stained with Hoechst (blue). (H) Quantification of percentage in CK19 positive cells, as well as percentage of $\mathrm{pS} 10 \mathrm{HH} 3$ positive cells in $\mathrm{DBA}$ positive and negative ducts were analyzed and expressed as mean \pm SEM. ${ }^{*} \mathrm{P}<0.05 \mathrm{KNGC}$ mice versus the other genotypes. 
Figure 7. Agr2 and Aqp5, but not DBA staining is enriched in human IPMN. Immunofluorescence staining of Agr2 (red), DBA-FITC (green) and CK19 (Cyan) (A) and immunohistochemistry staining of Aqp5 (B) from serial sections of a TMA containing human IPMN. White boxes indicated area magnified. Nuclei were counterstained with Hoechst (blue) in (A). N: Normal control. (C) Histological score (Hscore) of Agr2, Aqp5 and DBA staining in 140 samples of human IPMN were calculated and graphed. Shown was mean \pm SD. Black diamond: Mean value. Black line: Median value. ${ }^{*} \mathrm{P}<0.05$ Agr2 versus DBA. \#P<0.05 Aqp5 versus DBA. (D) Scatter plot with loess fit line and 95\% confidence limits (colored area) for Agr2 in overall samples (Left) and IPMN with adenocarcinoma (Right) were drawn and Spearman correlation coefficient were calculated with P-value. (E) Schematic summary of terminal ducts as cell-of-origin of IPMN. PDX1 ${ }^{+}$pancreatic progenitor cells develop into normal pancreas (left) or lowgrade IPMN with visible cysts in KNGC mice (right). Histological examination shows various markers described for each colored compartment of exocrine pancreas tissue including acinar (purple), centroacinar (CA, yellow), terminal ducts (TD, red) and main ducts/interlobular ducts (MD/ID, green). 
Figure 1

A

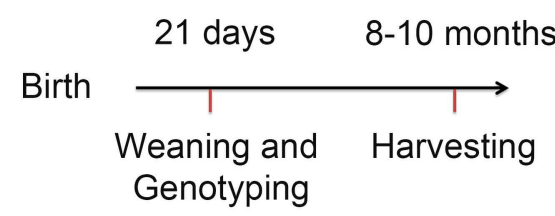

B
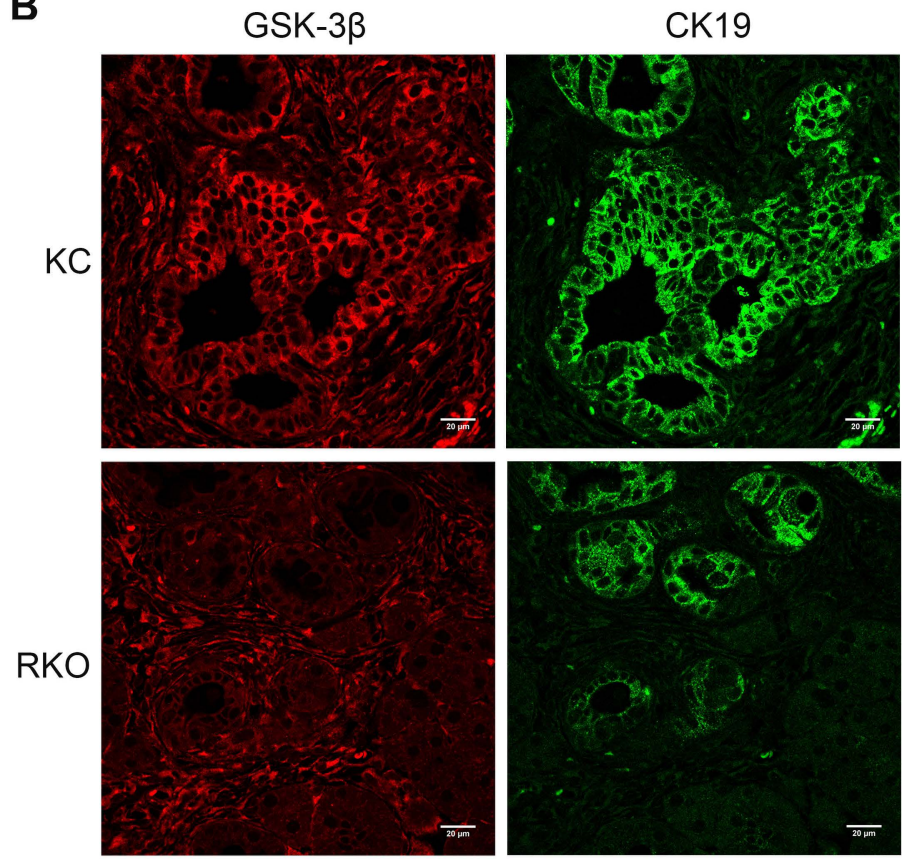

D

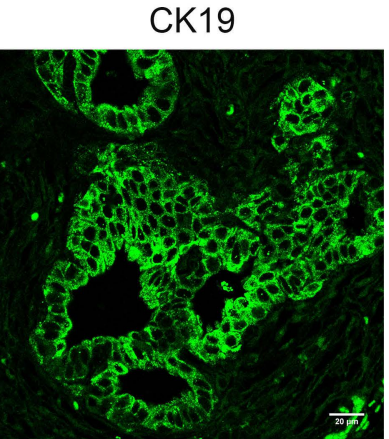

$\frac{-3}{2007}$ "
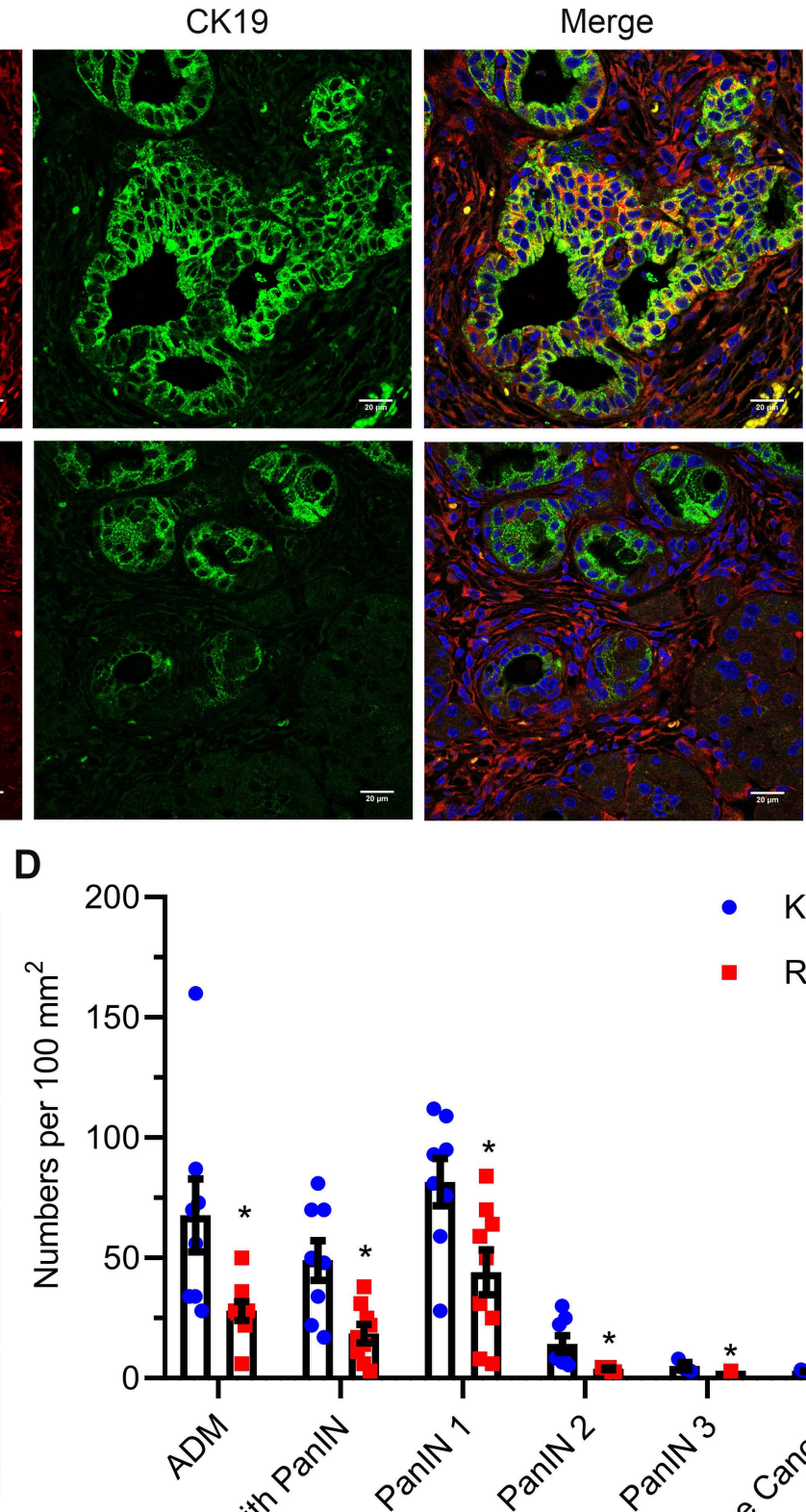

- $\mathrm{KC}(\mathrm{n}=8)$

- $\operatorname{RKO}(n=9)$
CK19
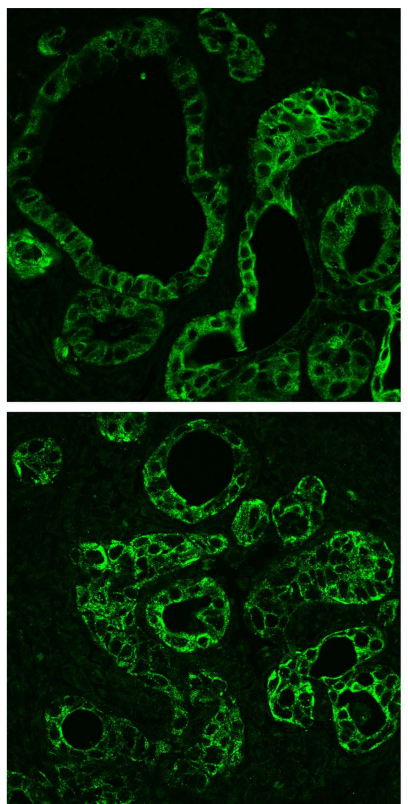

E

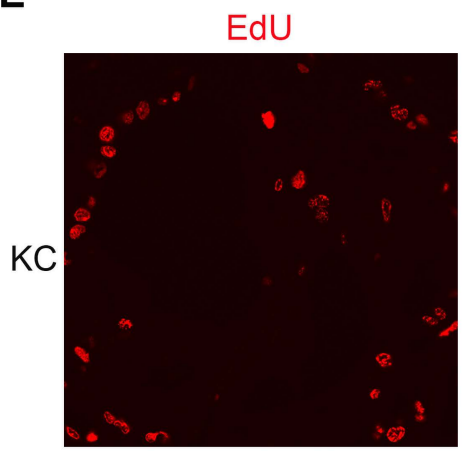

$40 \mathrm{X}$

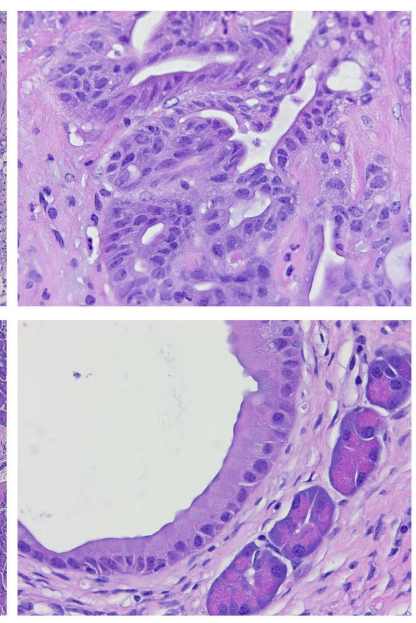

RKO

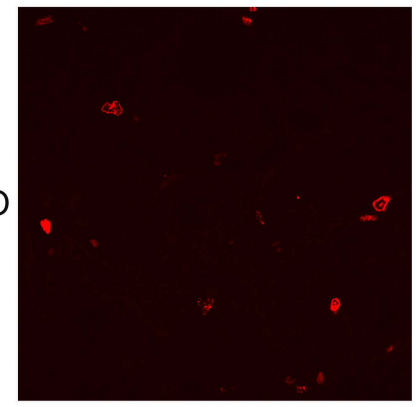

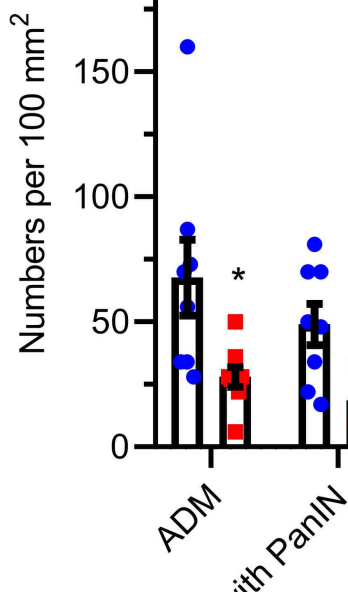

- $\mathrm{KC}(\mathrm{n}=6)$

- $R K O(n=6)$

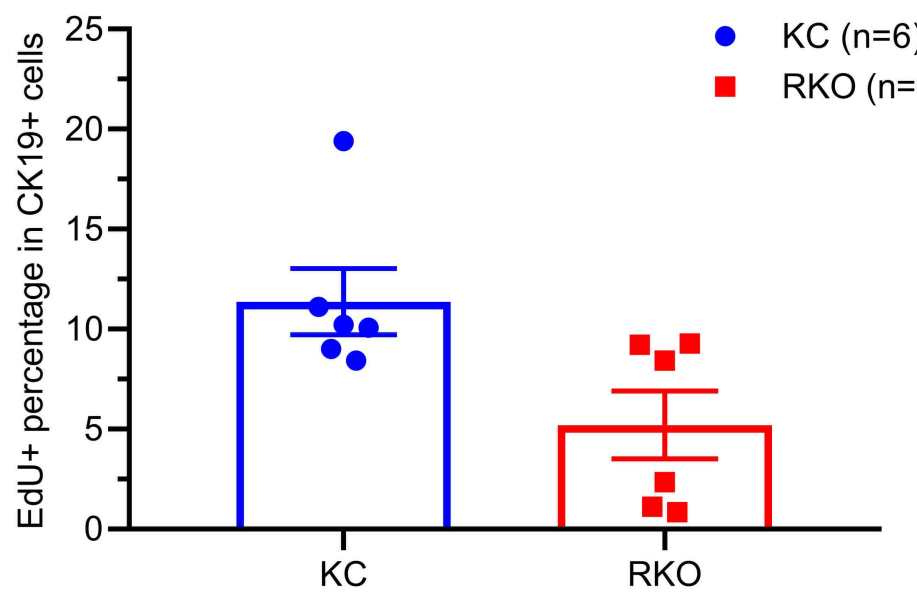


Figure 2

A

$\stackrel{\text { Pdx1 } 1}{\longrightarrow} \underset{C r e-}{\longrightarrow}$

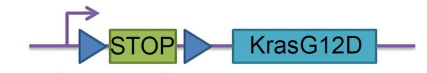

Loxp Loxp

Rosa26

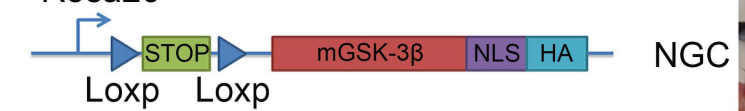

B

4 wks biahxiv preprigtctoi: htres://dikpugte. 1101/2020 f

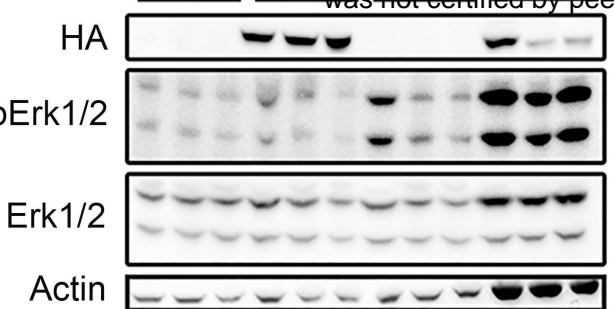

E

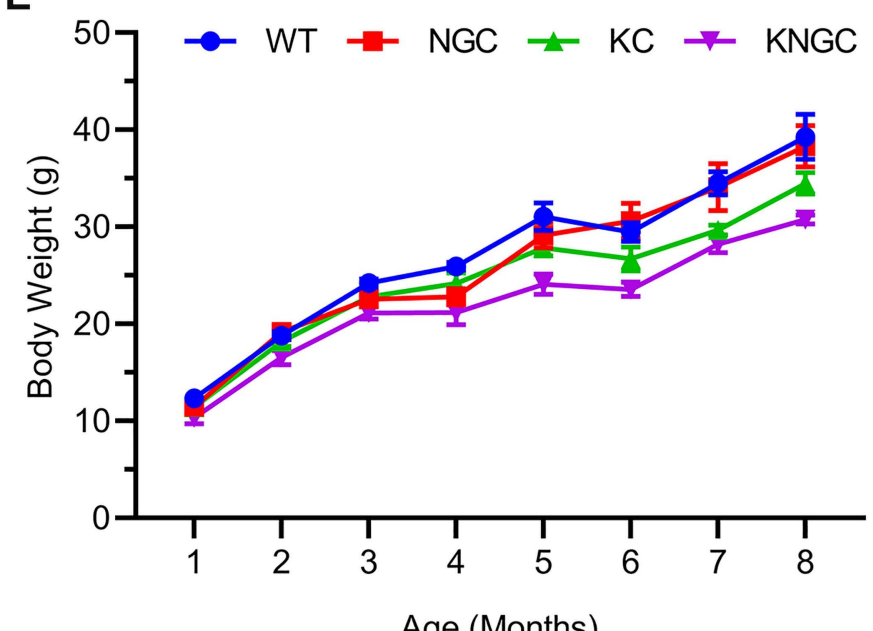

4 wks

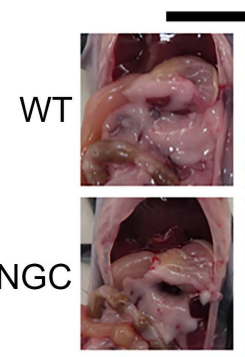

KNGC

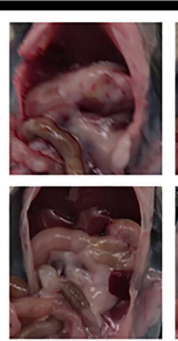

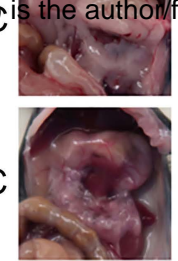

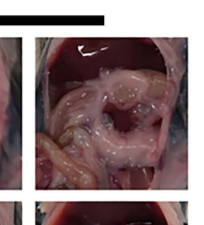

D

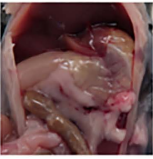

WT

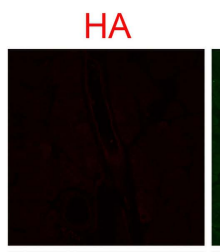

aSMA

CK19
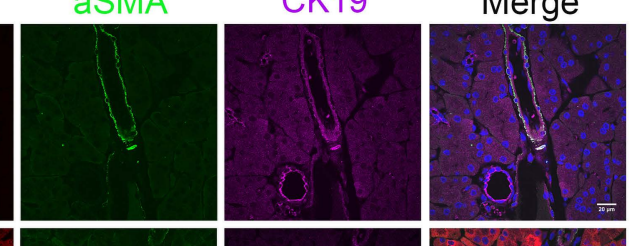

NGC
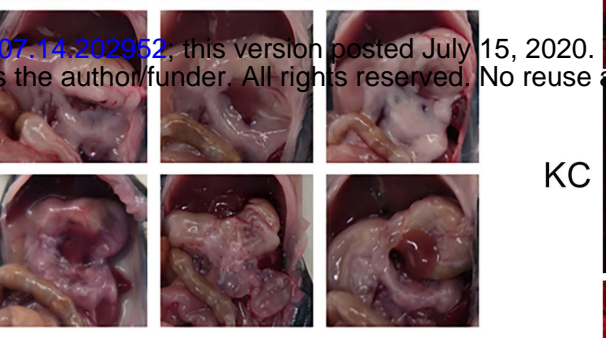

KNGC

KC

F

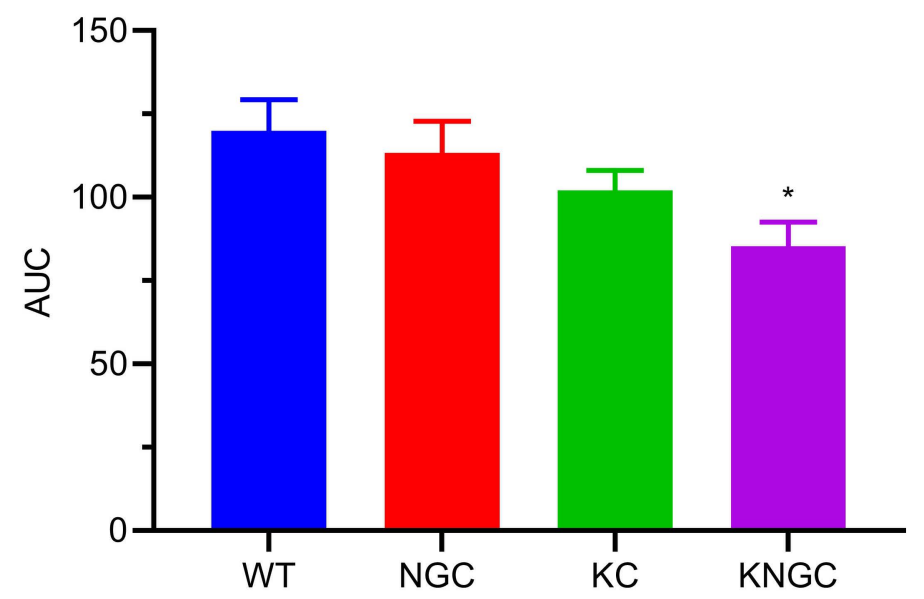

H

4 wks

4 months

8 months
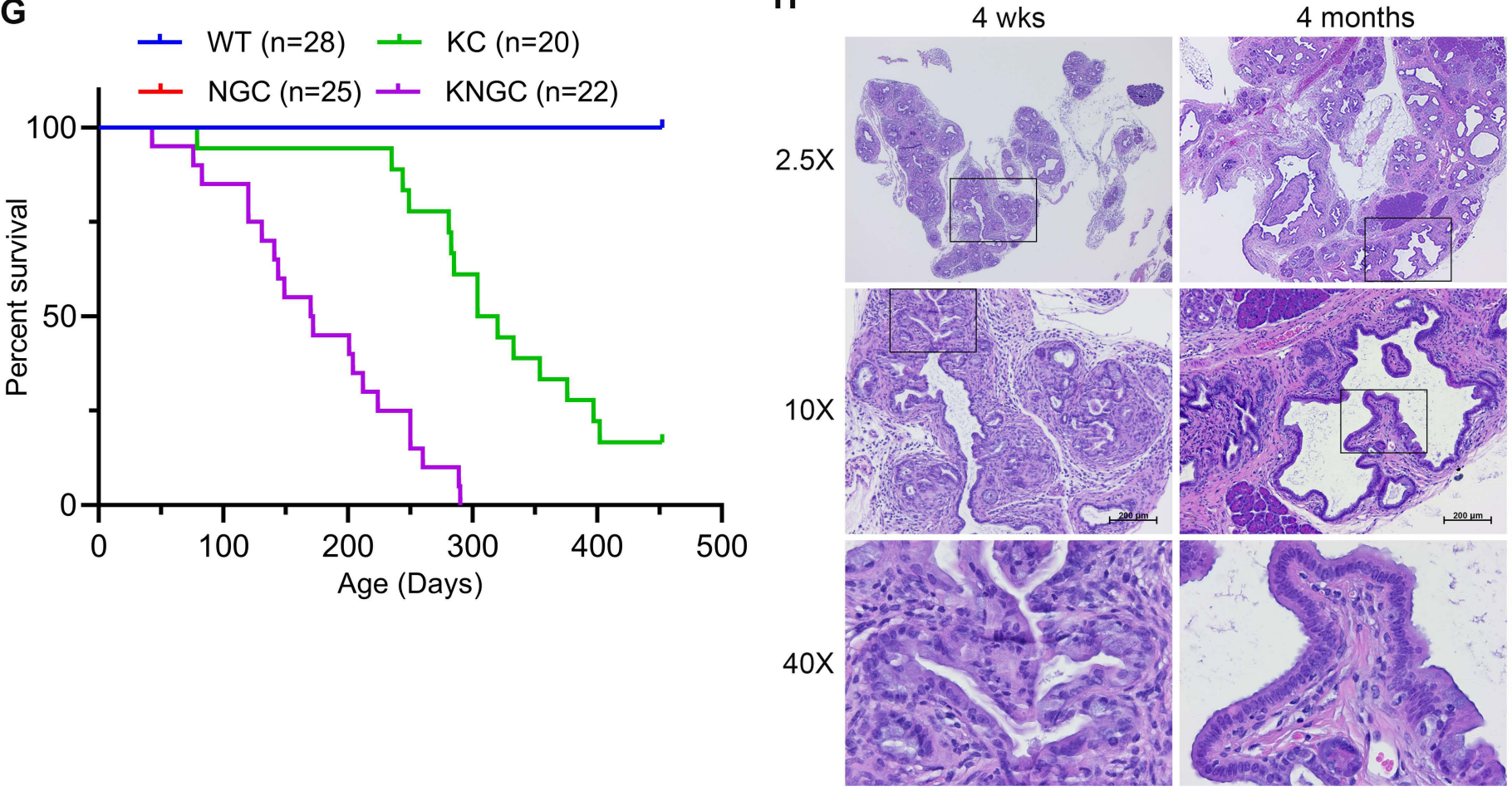

J
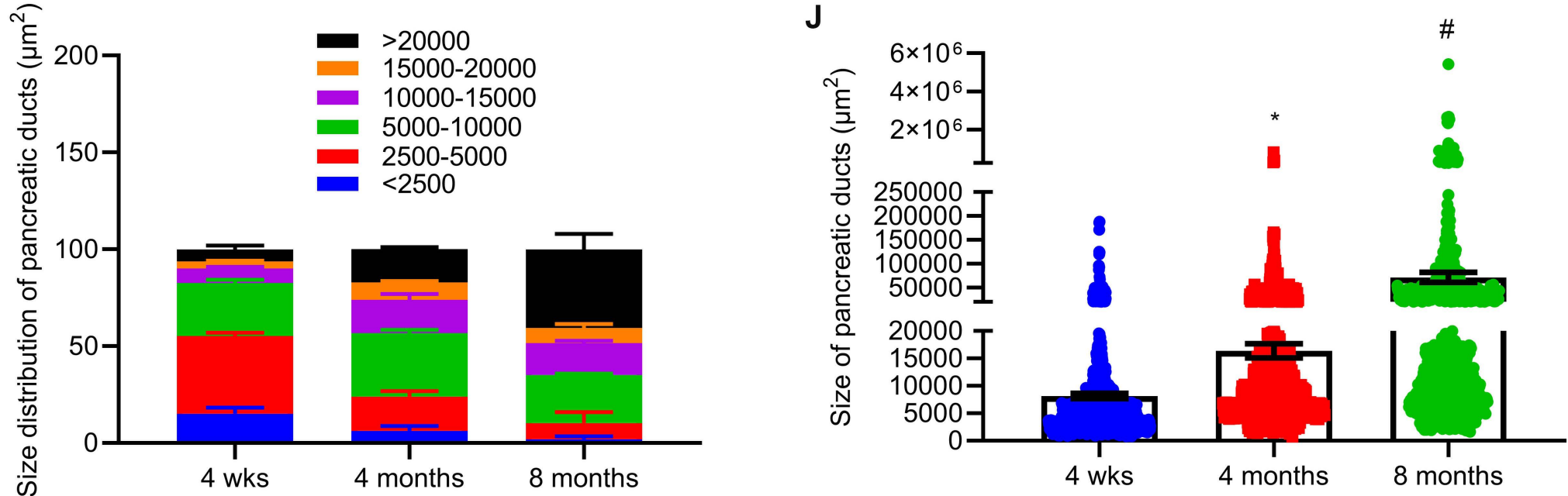
A

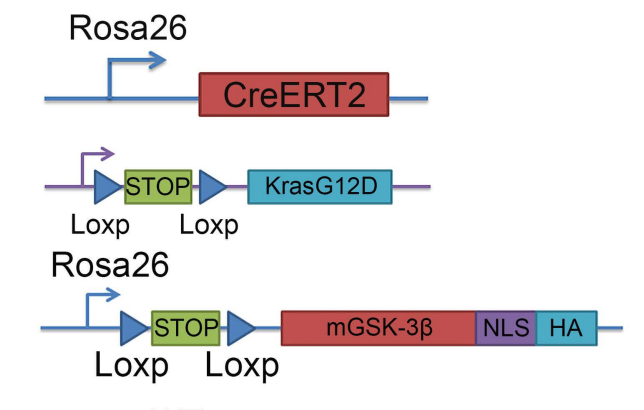

Pan-Keratin

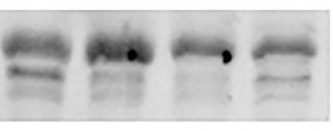

KrasG12D

$\begin{gathered}\text { Tubulin } \\ \text { actin } \\ \text { GAPDH }\end{gathered}-$

C

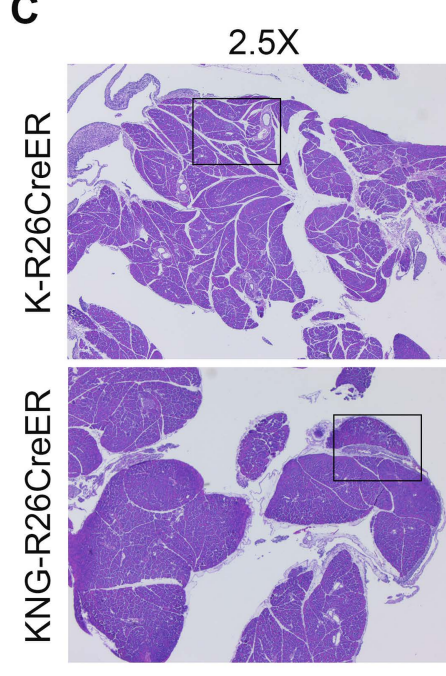

D
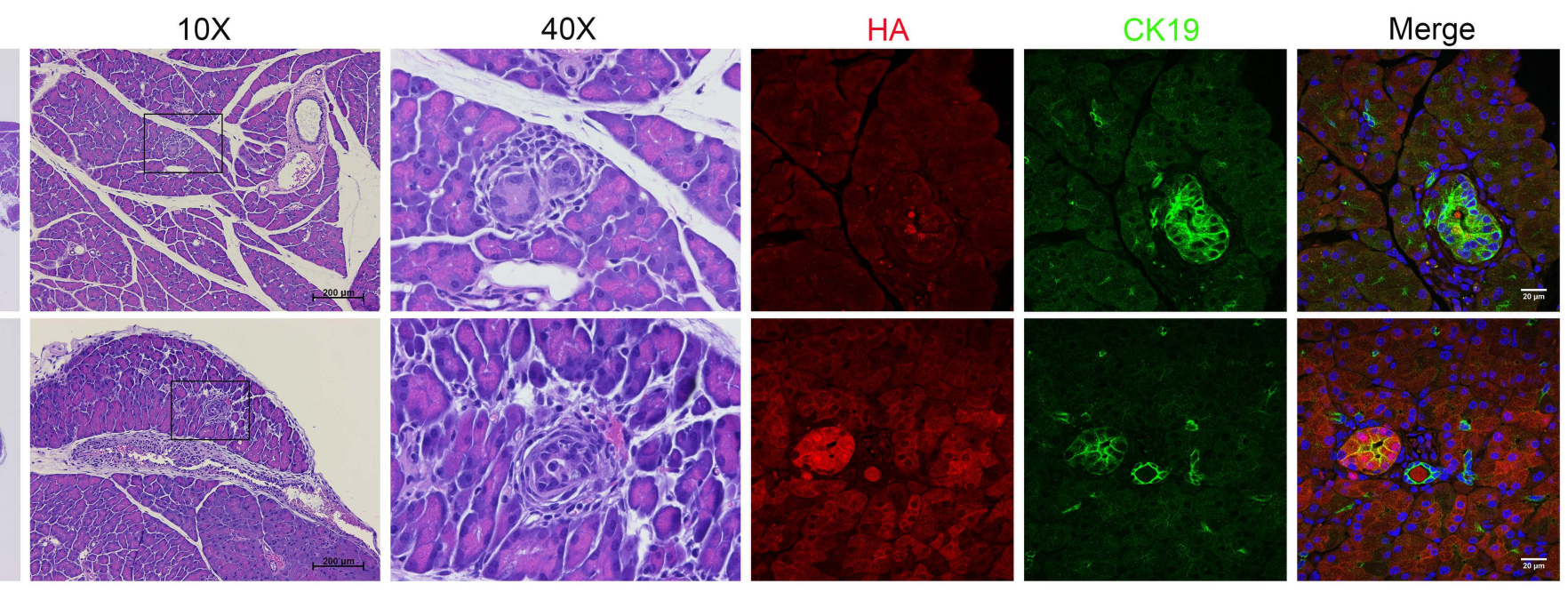

E

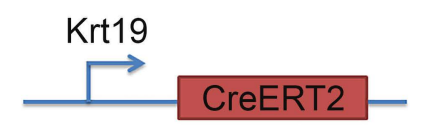

$\overrightarrow{\text { STOPA }}_{\text {KrasG } 12 \mathrm{D}-}$ Loxp Loxp

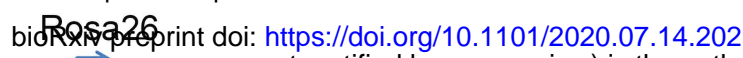

STOP. Was not certitifed by peer review) is Loxp Loxp

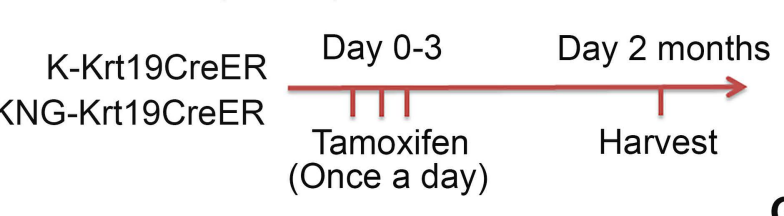

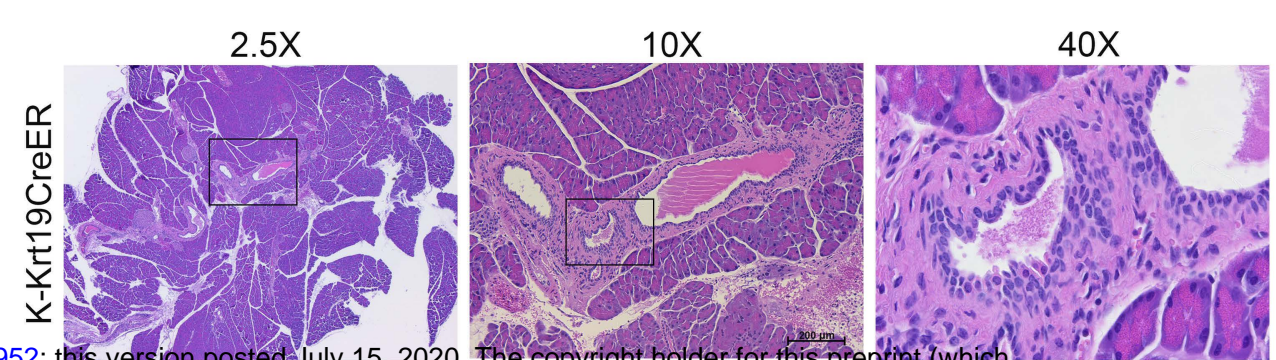

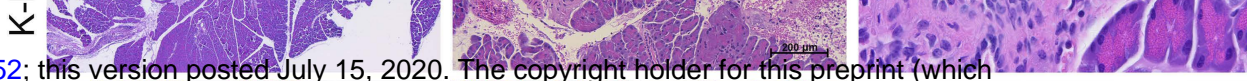
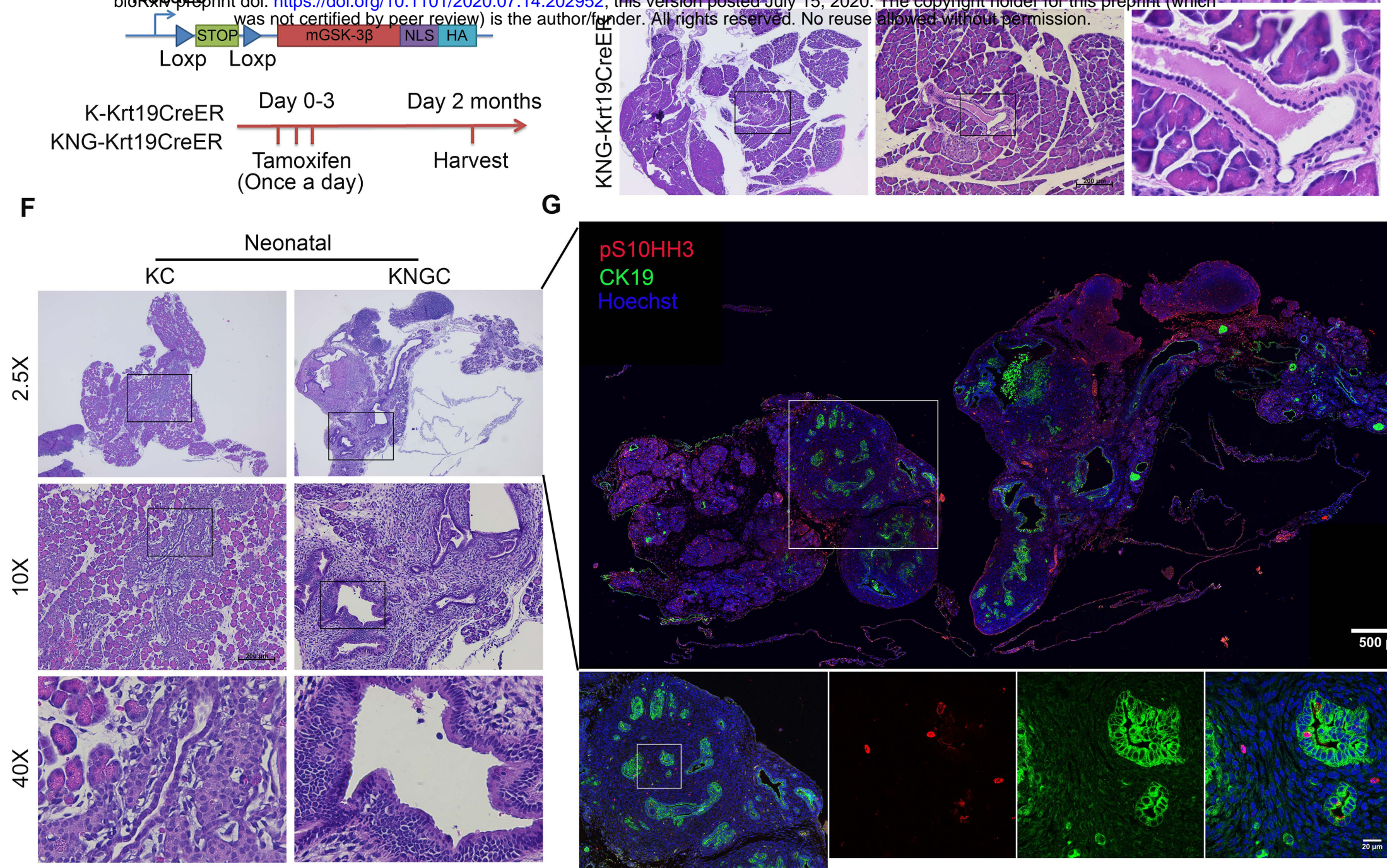

$$
\text { c }
$$
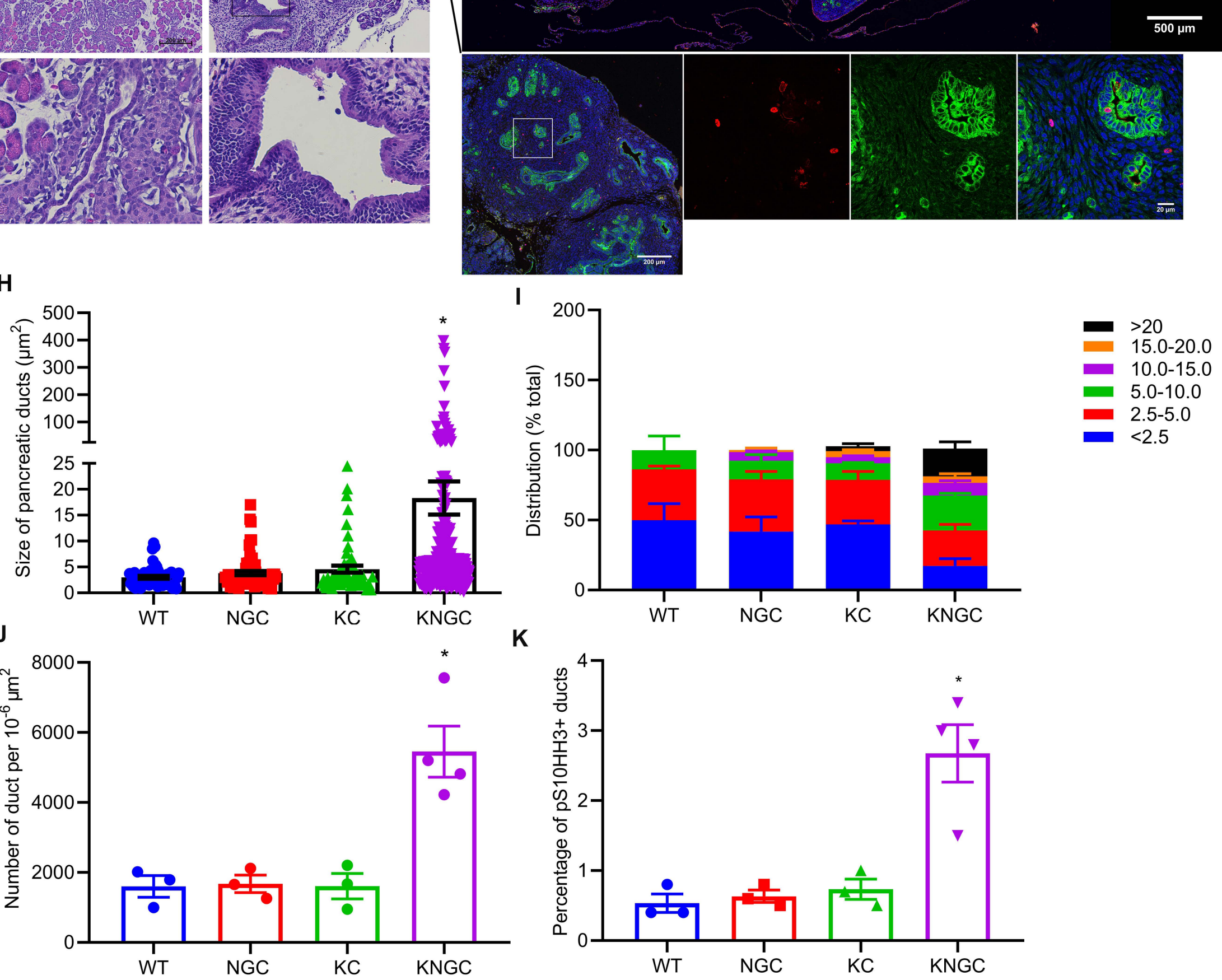
Cell morphogenesis involved in differentiation

Regulation of cell differentiation

Regulation of stem cell proliferation

Cell proliferation

Regulation of epithelial cell proliferation

Positive regulation of cell proliferation

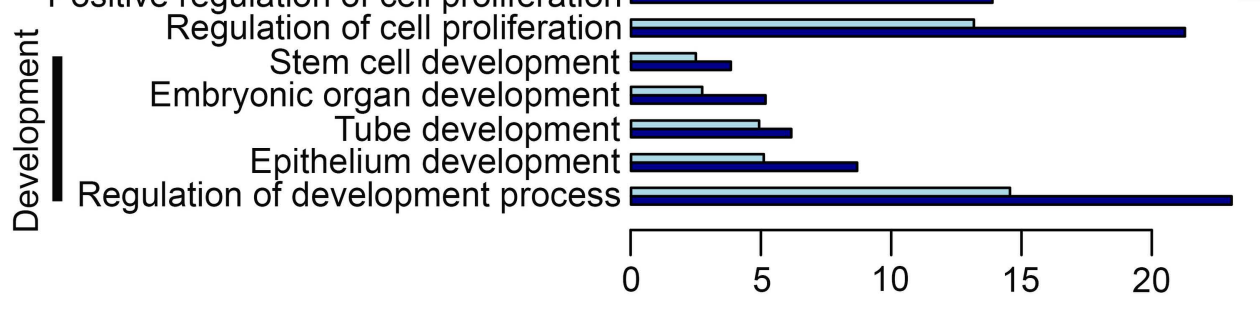

B

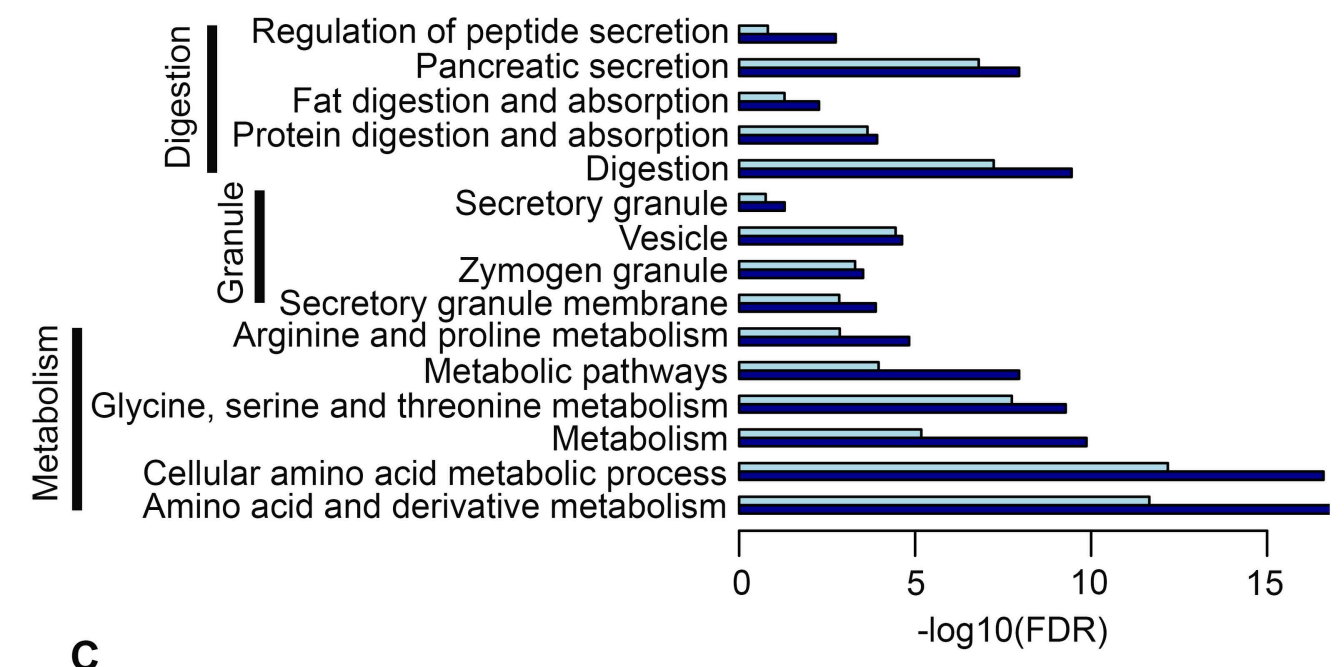

C

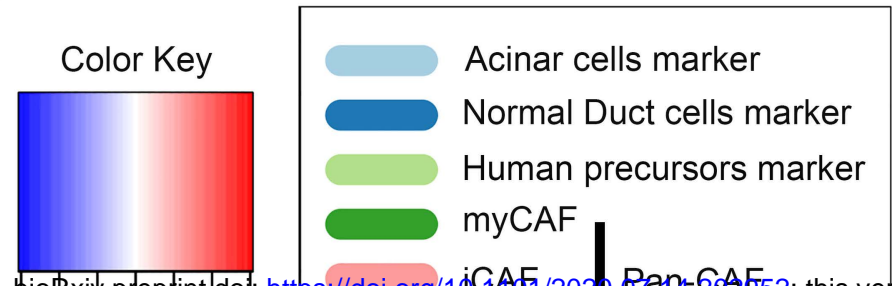

E

80
$60-1$
$40-1$
$20-1$

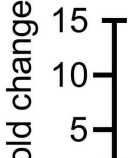

1

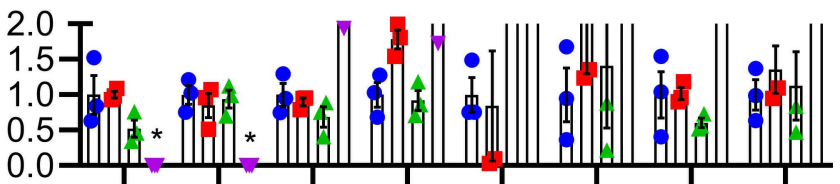

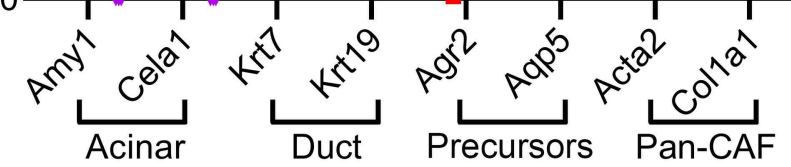

G

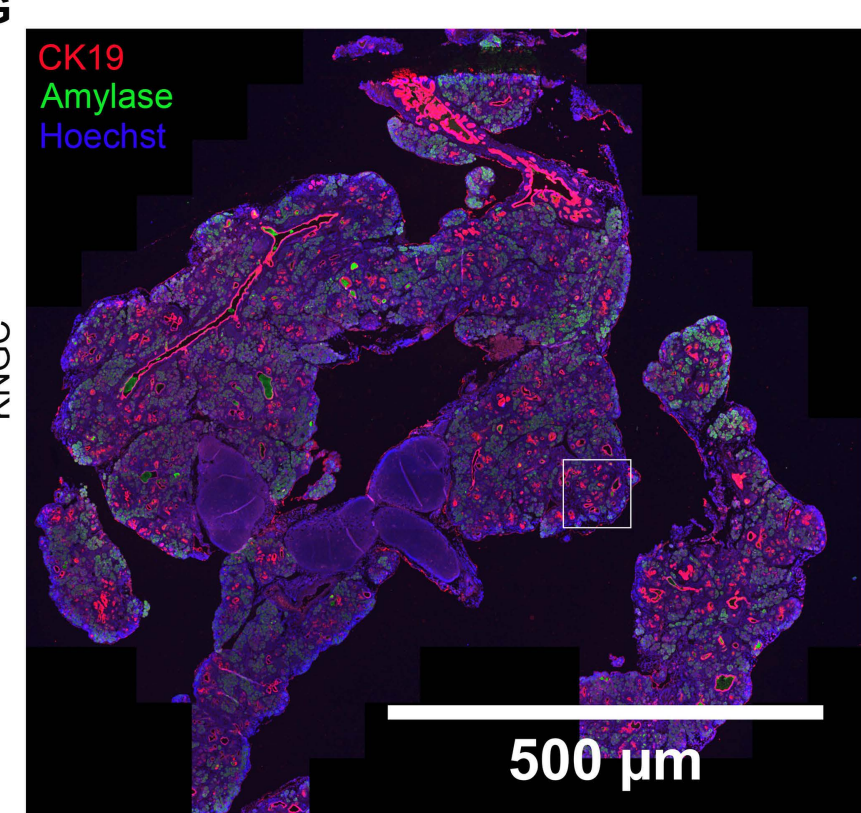

H
WT NGC KC KNGC

Pan-Keratin a

Amylase ๘

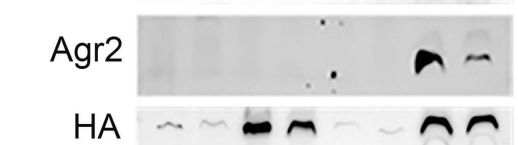

Tubulin $-\infty \cdots \cdots \cdots$

actin $-\cdots-\cdots-\cdots$ GAPDH
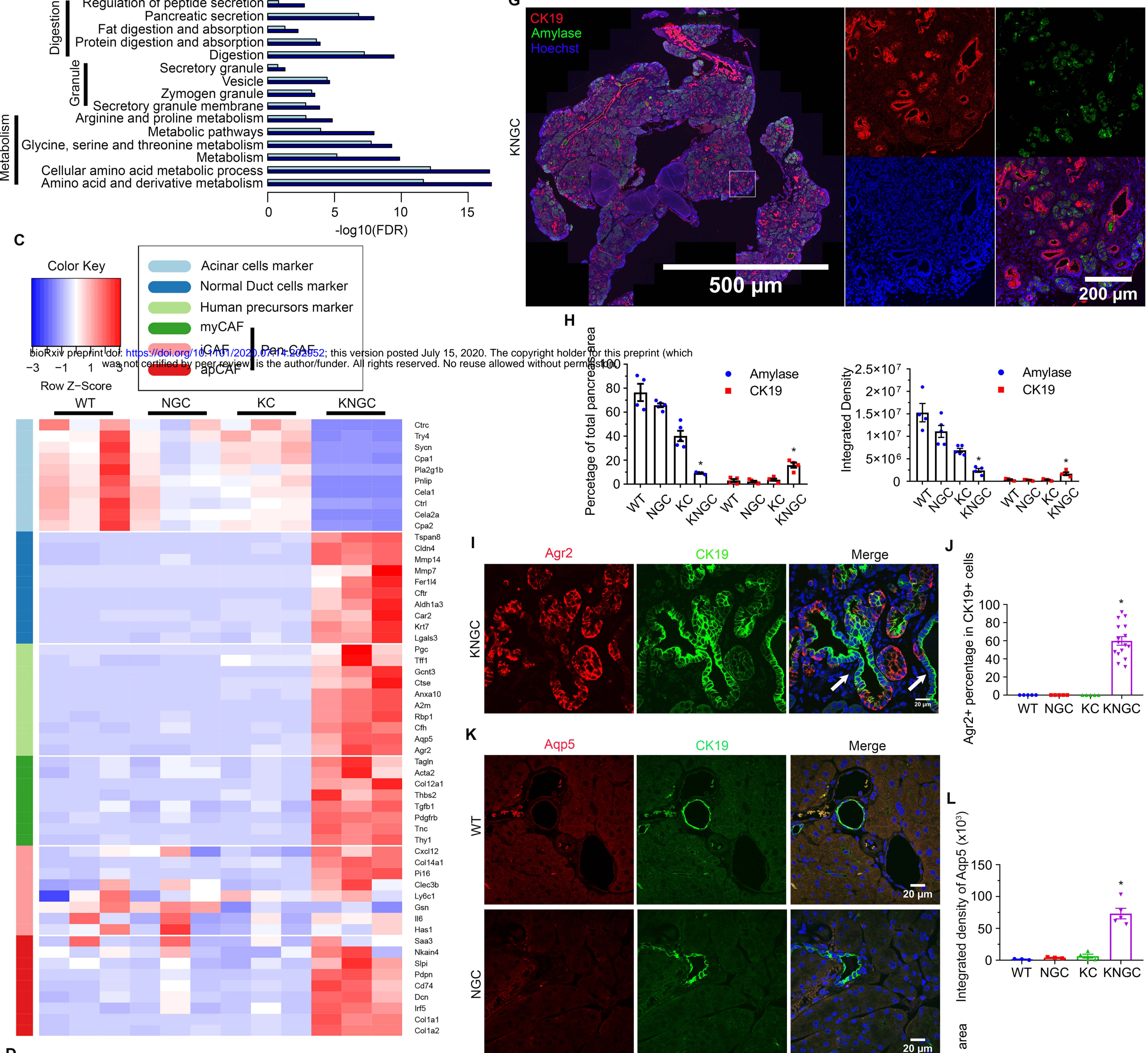

$200 \mathrm{um}$

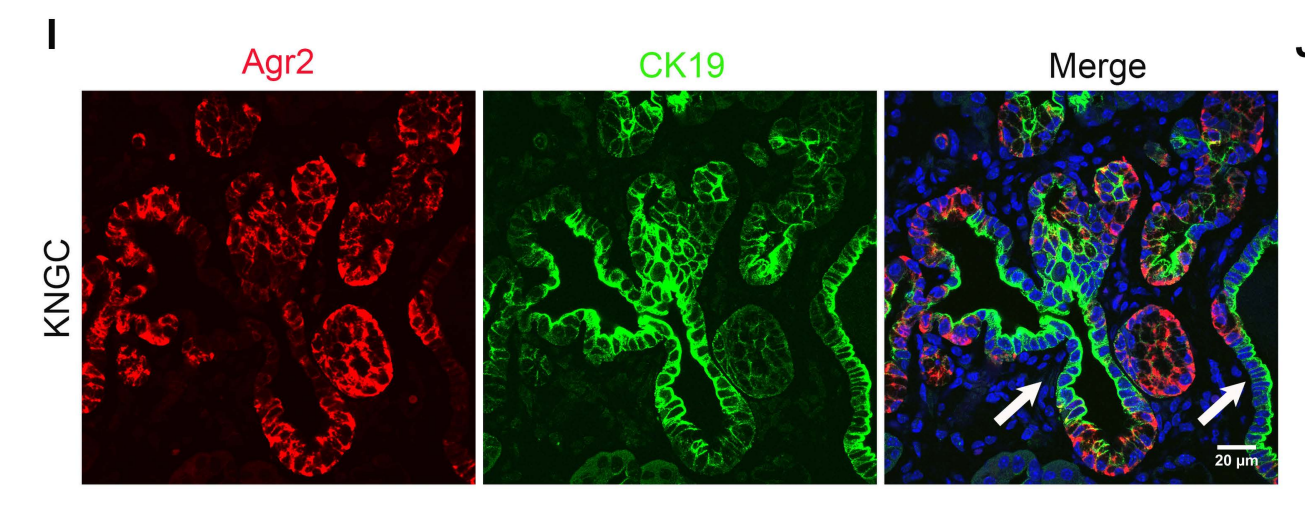

K
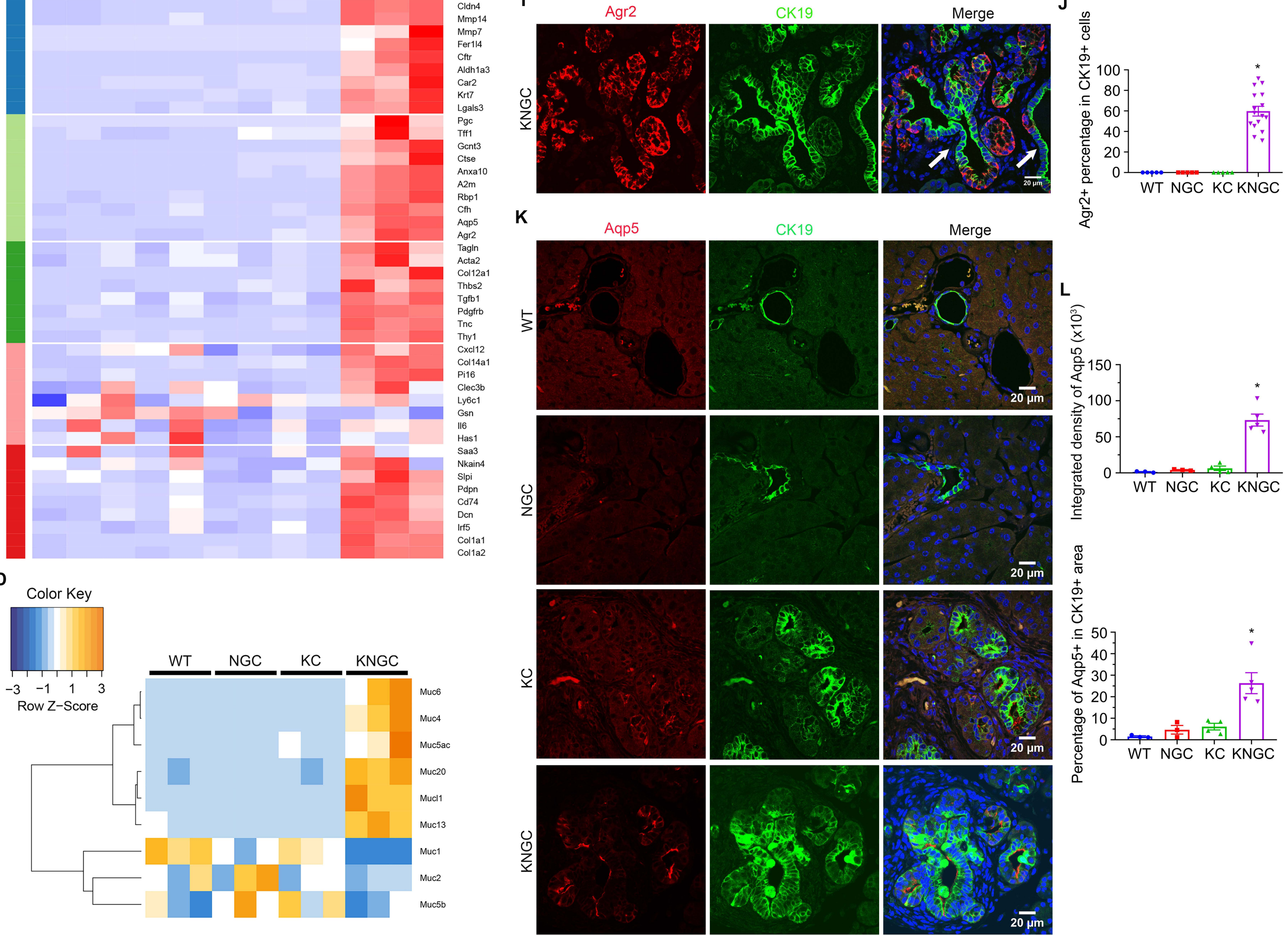


\section{Figure 5}

A bioRxiv preprint doi: https://doi.org/10.1101/2020.07.14.202952; this version postd July 15, 2020. The copyright holder for this preprint (which

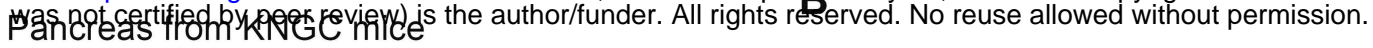
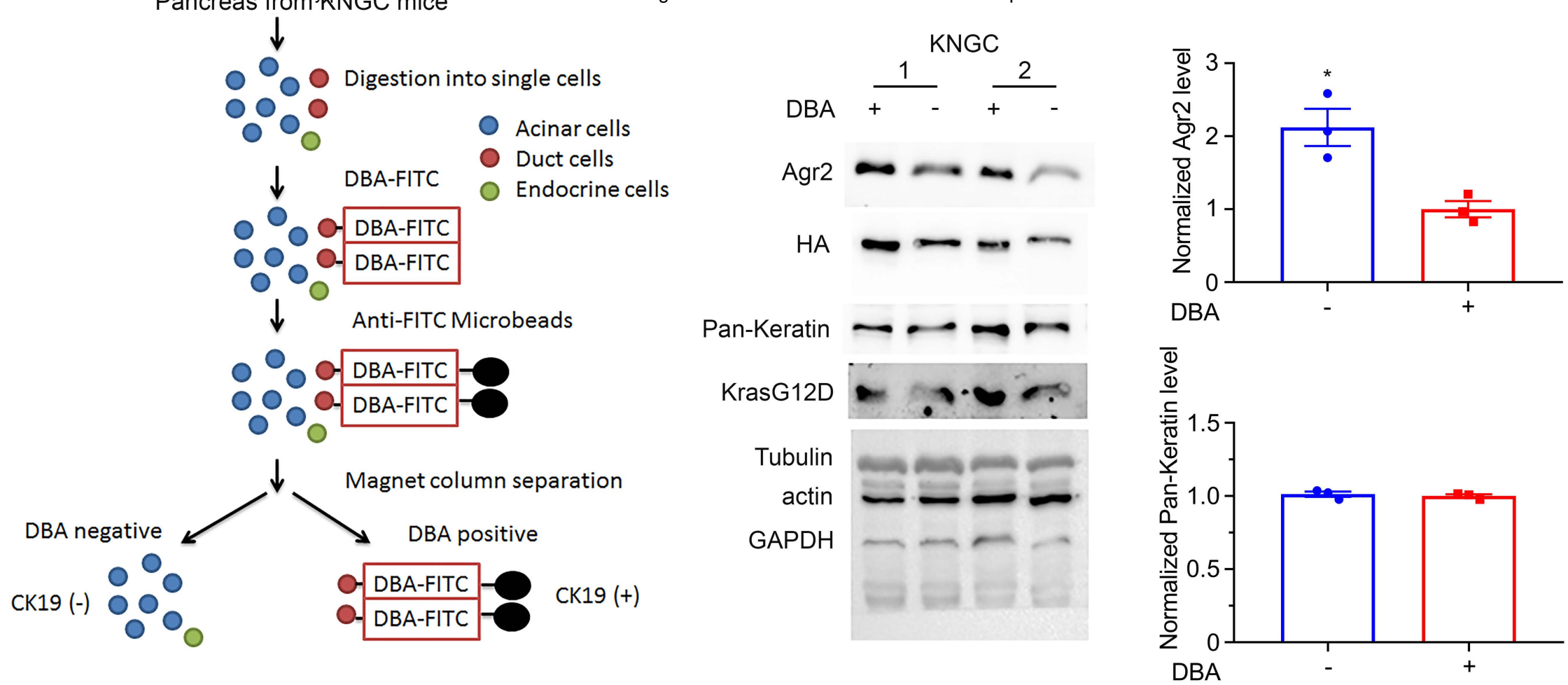

- $\quad$ Aging KC DBA (-) $\quad$ KNGC DBA (-)

- Aging KC DBA (+) $\nabla \operatorname{KNGC~DBA~(+)~}$

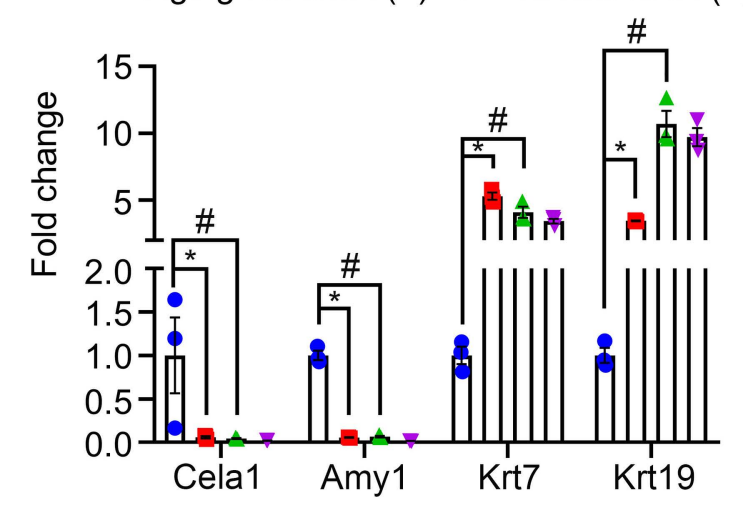

E Agr2

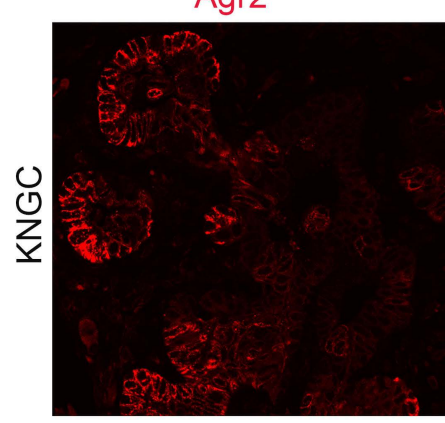

Aqp5
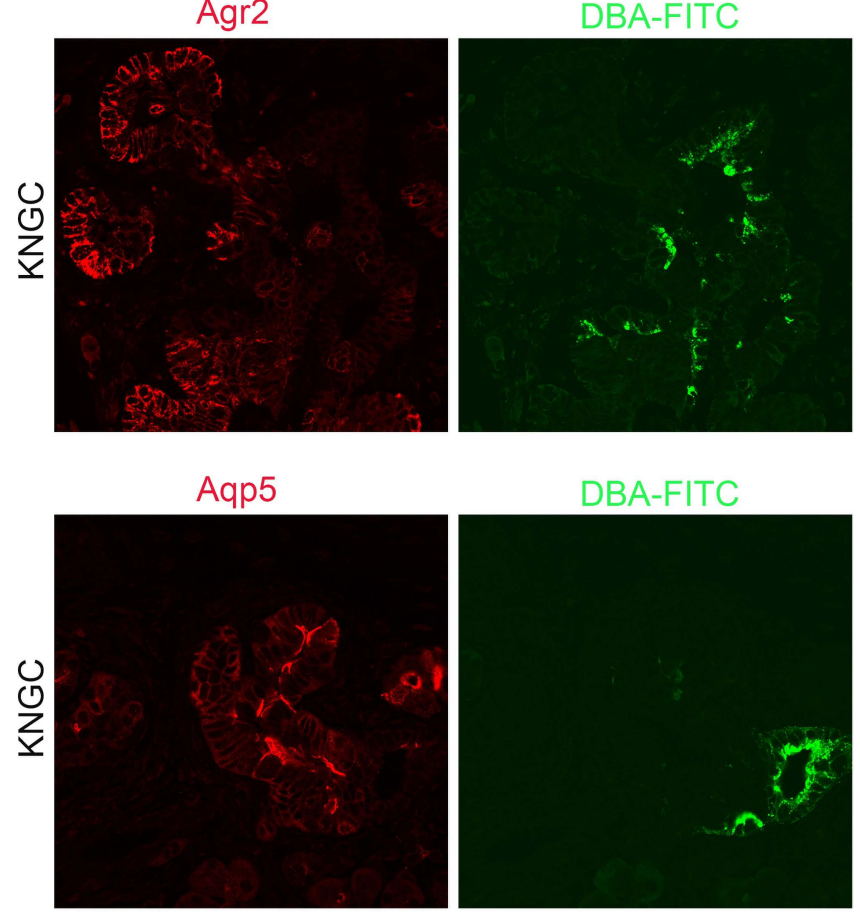

DBA-FITC

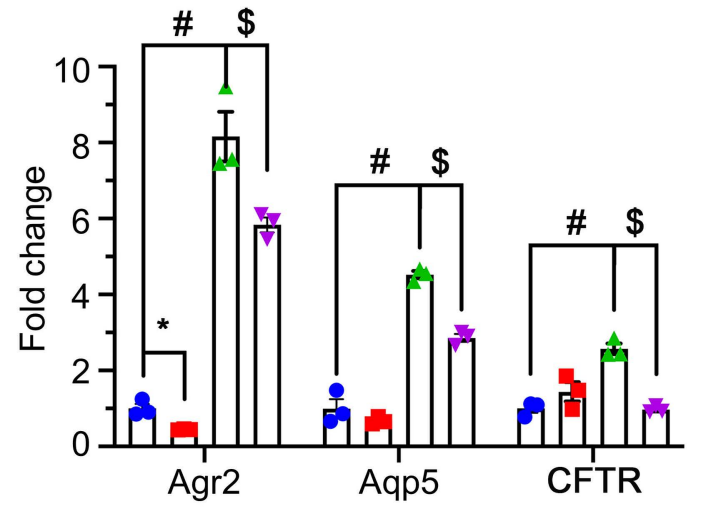

$\mathbf{F}$

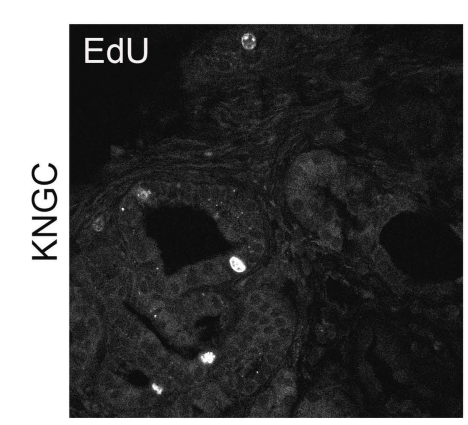

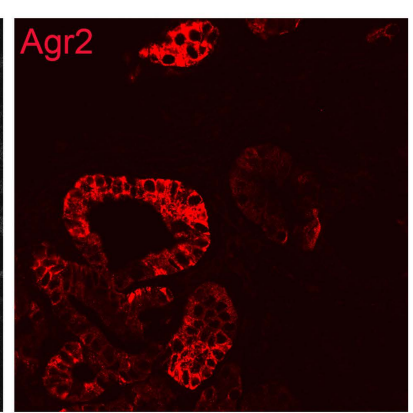

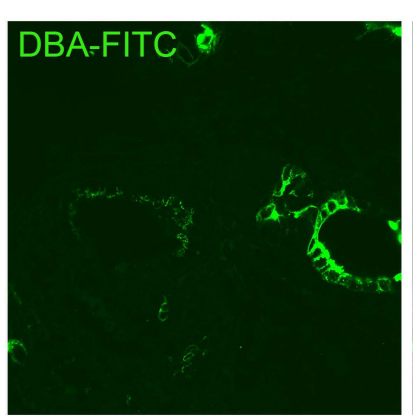

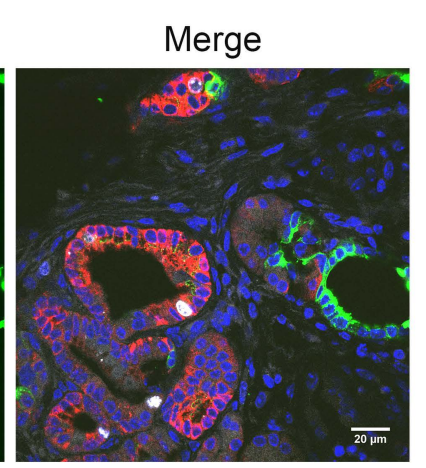

G

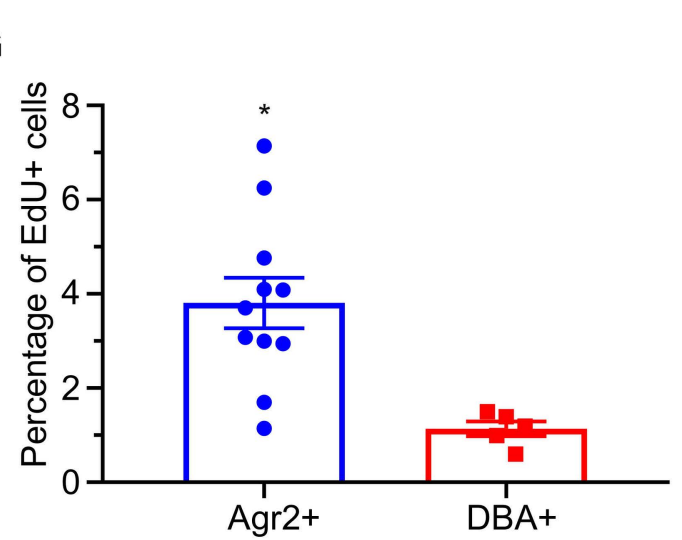

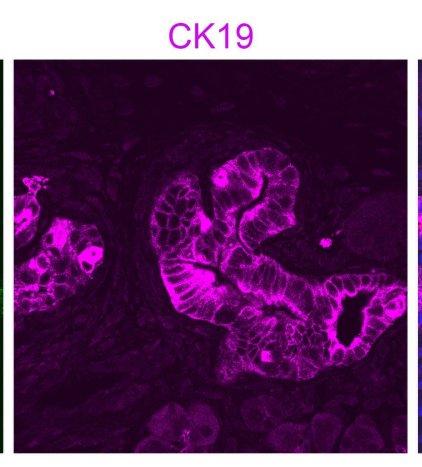

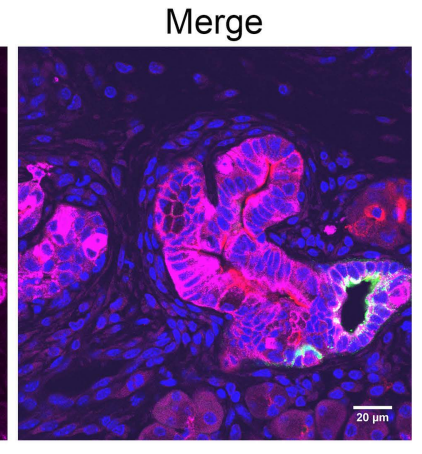

Merge

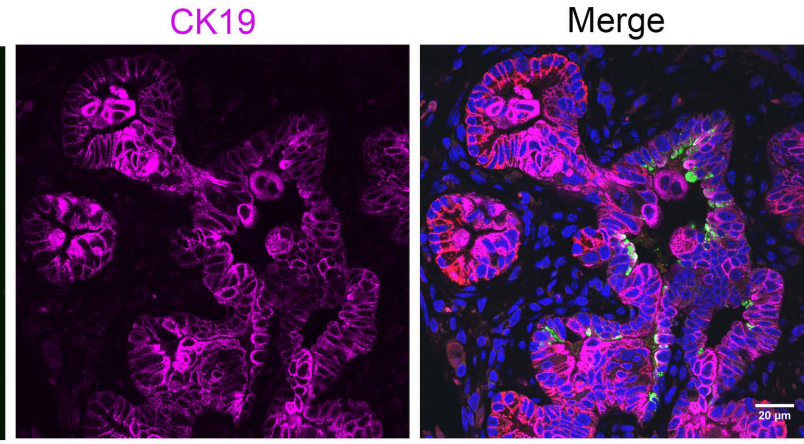



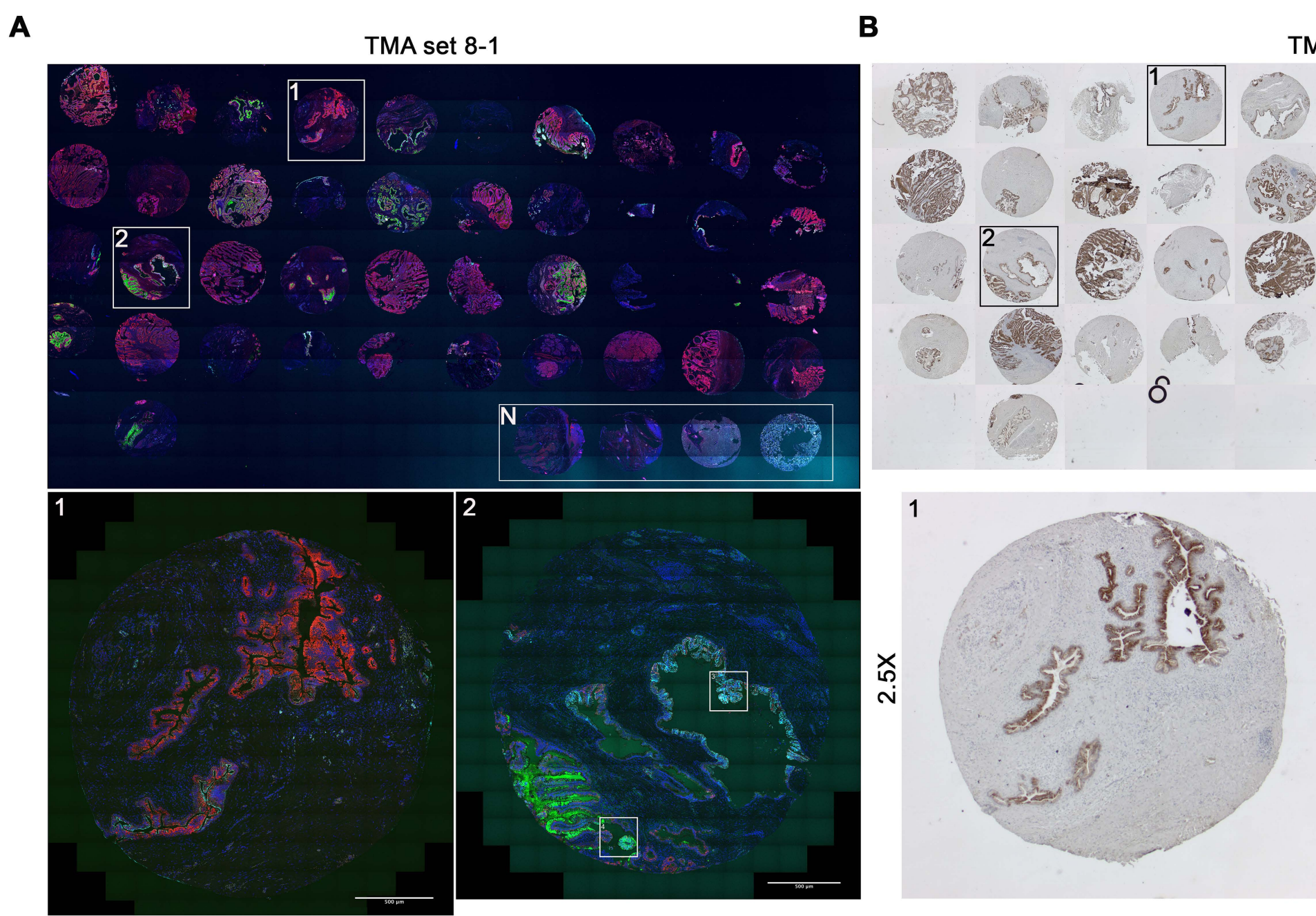

TMA set 8-2

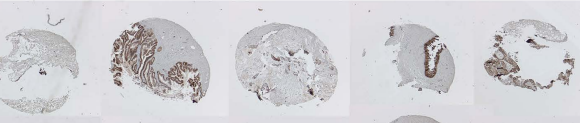
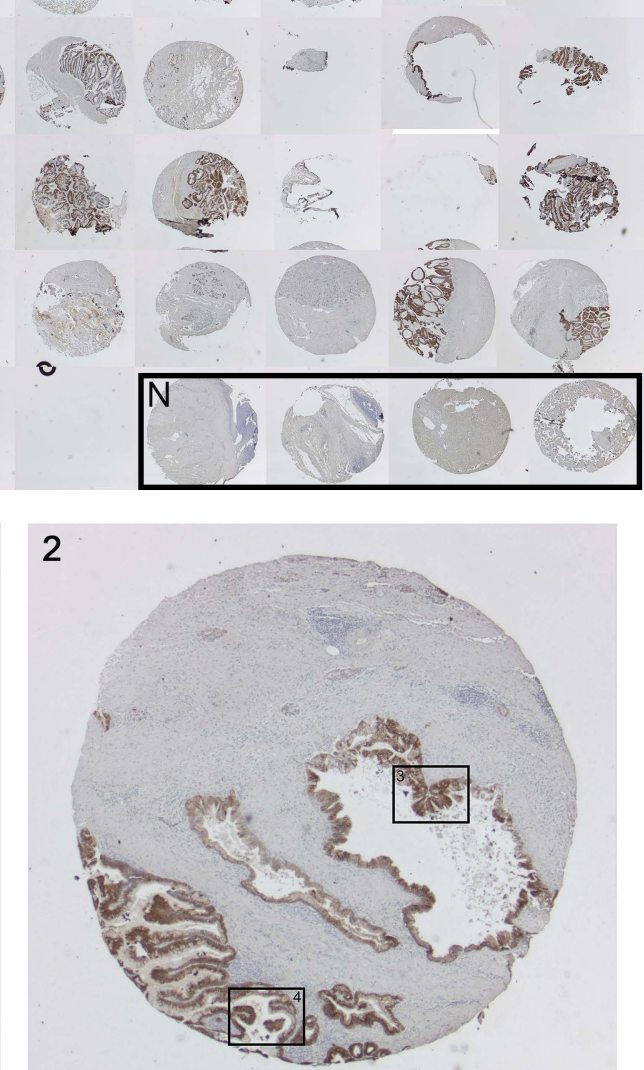

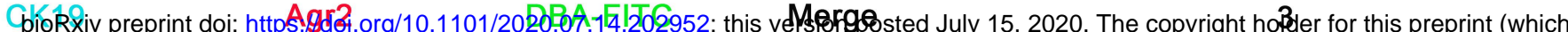
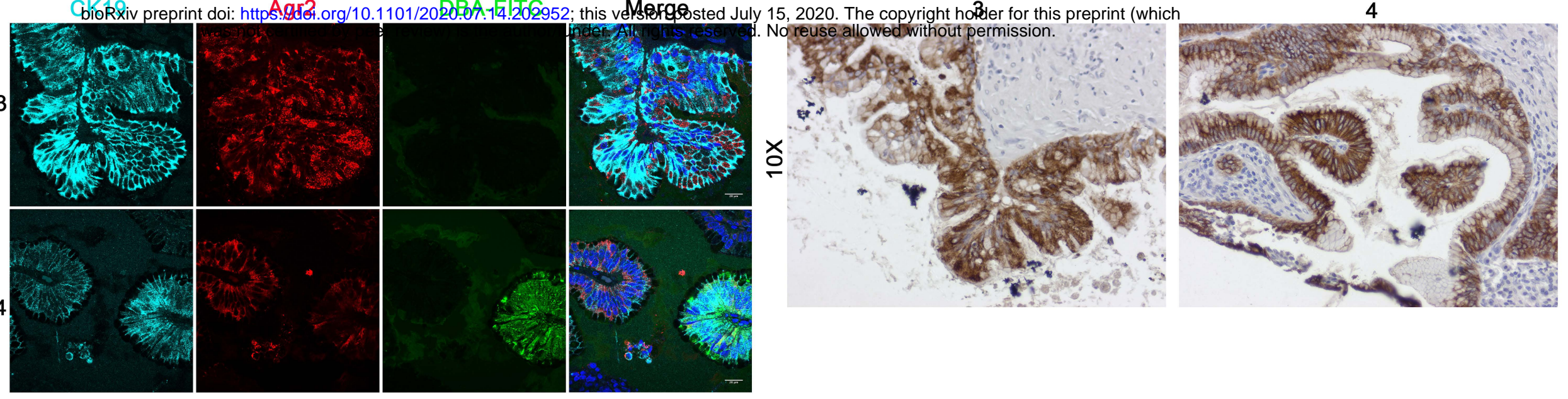

C

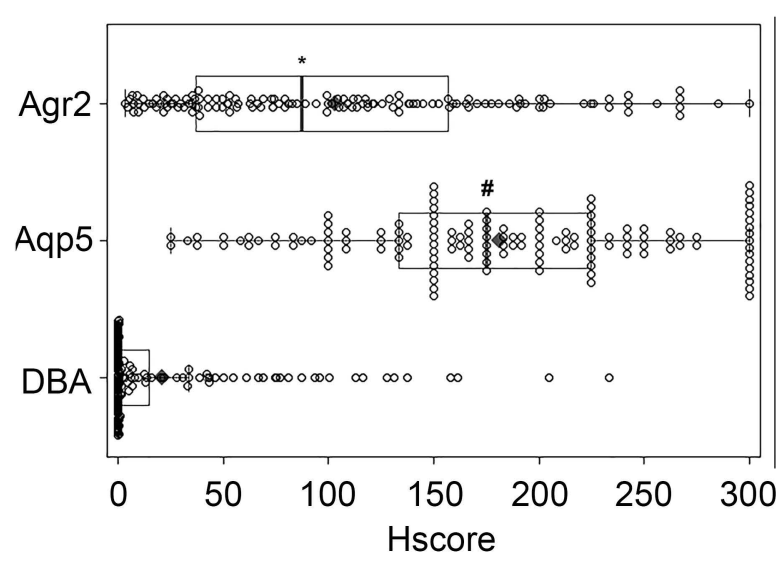

D
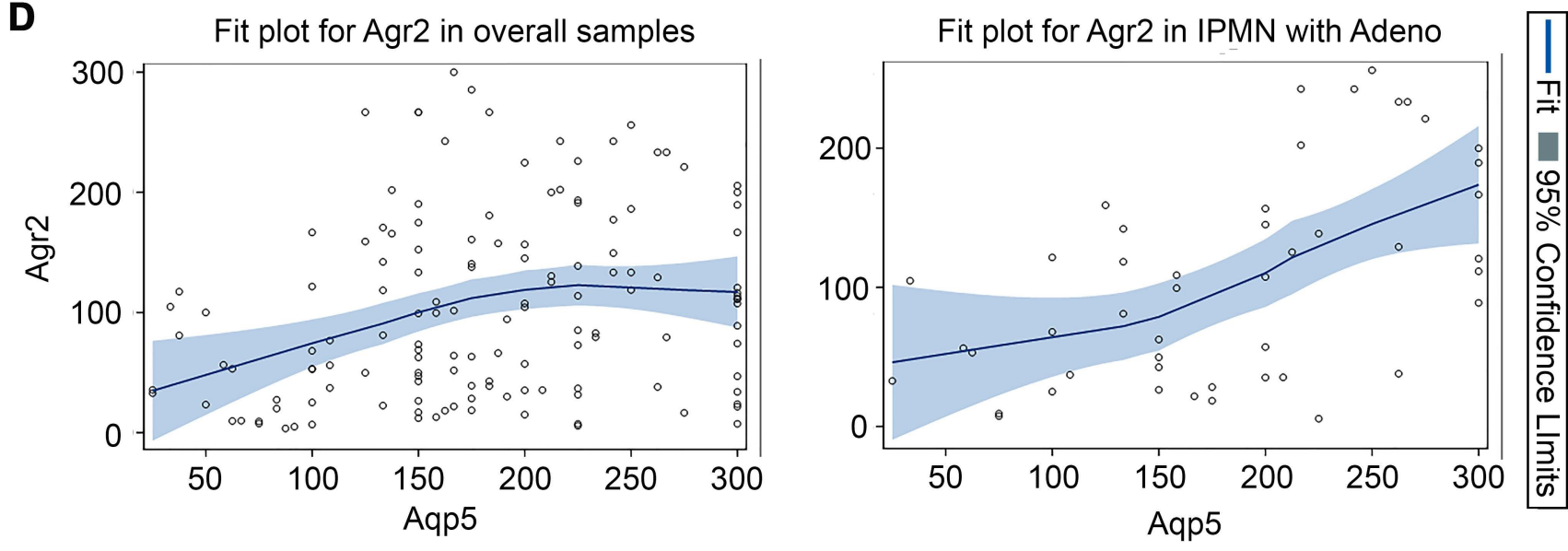

Spearman Correlation $=0.269$, p-value 0.0014

\section{$\diamond$ Mean I Median}

E

Pancreatic progenitor cells

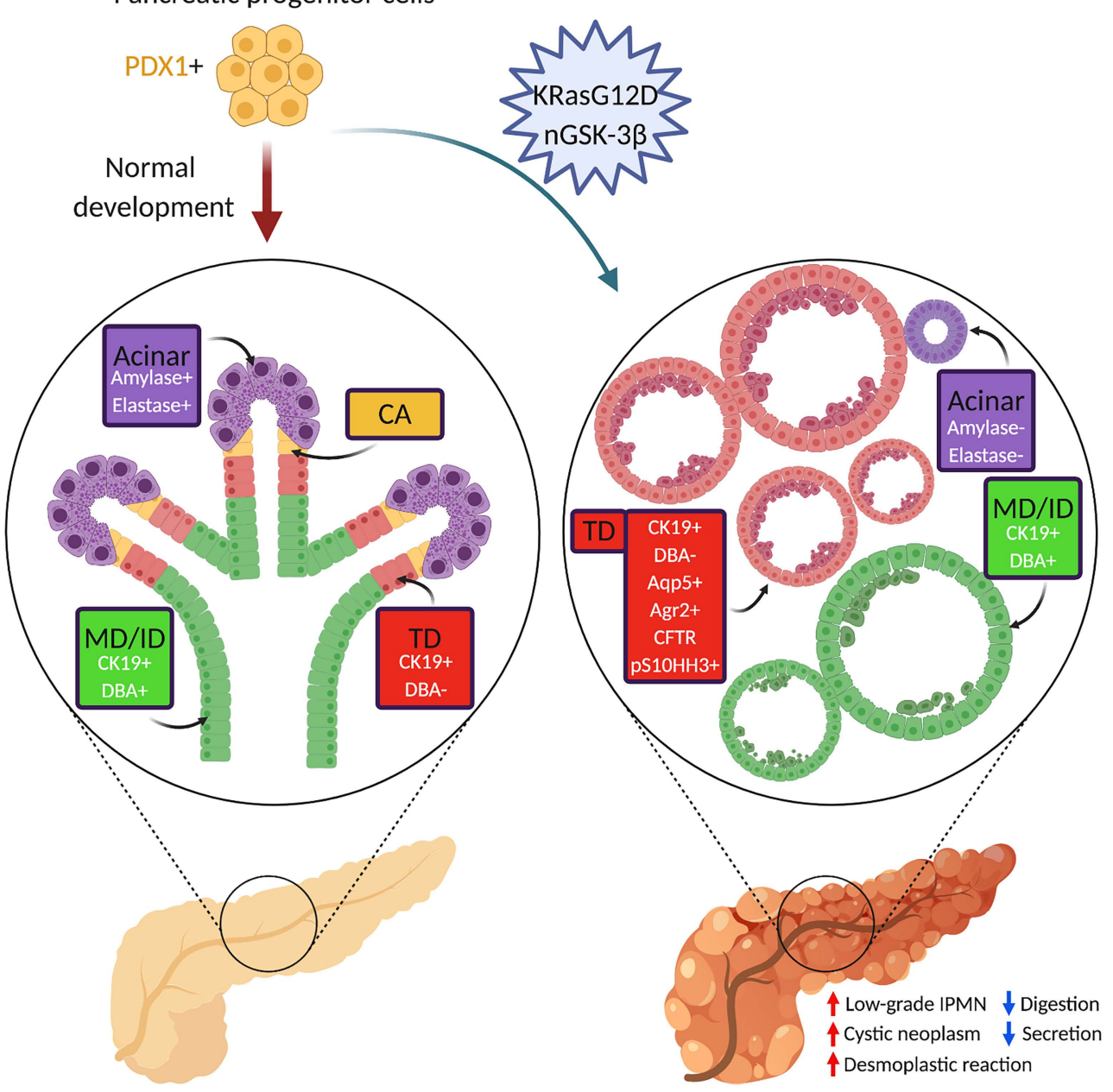

